\title{
ZnO Nanostructures Synthesized by Vapor Transport and Liquid Phase Synthesis Techniques: Growth and Properties
}

\author{
Oscar Marin*, Silvina C. Real*, Nadia Celeste Vega*, Mónica Tirado, and David \\ Comedi**
}

NanoProject, Departamento de Física, Facultad de Ciencias Exactas y Tecnología, Universidad Nacional de Tucumán (UNT) and Instituto de Física del Noroeste Argentino - INFINOA (CONICET-UNT), San Miguel de Tucumán, Argentina.

* These authors contributed equally to this work.

${ }^{* *}$ Corresponding author. E-mail: dcomedi@herrera.unt.edu.ar

\begin{abstract}
In this review, we briefly describe work devoted in recent years towards the effective control of morphology, structure and optical properties of $\mathrm{ZnO}$ nanostructures, with particular focus on cost effective and simple methods for $\mathrm{ZnO}$ nanowires (NWs) fabrication. For the vapor transport technique, we describe in detail mechanisms for growth precursors generation, their transport in inert and forming gas, as well as their reactions on different pretreated substrates and corresponding growth mechanisms. As for low temperature synthesis methods, three techniques are outlined:

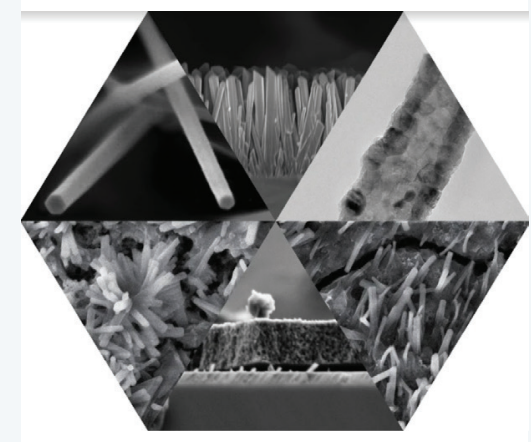
sol-gel, solvothermal and electrophoretic deposition, with emphasis on effective morphology, structure and optical properties control. In this context, we discuss recent attempts to understand the role of solvent and alkaline agents used during solvothermal synthesis of $\mathrm{ZnO}$ nanostructures on their morphology and photoluminescence properties. Recent success of electrophoretic deposition of $\mathrm{ZnO}$ nanoparticles on pre-patterned silicon substrates in the form of NWs and NW bunches is highlighted over many previous attempts to fabricate $\mathrm{ZnO} N W s$ with inconvenient sacrificial templates. Finally, we present a critical discussion on the current understanding of passivation mechanisms of $\mathrm{ZnO} N W$ surfaces by MgO shells.
\end{abstract}

\section{Keywords:}

$\mathrm{ZnO}$ nanowires, semiconductor nanostructures, electrophoretic deposition, solvothermal synthesis, vapor transport deposition

\section{Introduction}

As a result of the rapid progress of modern microelectronics and nanophotonics, semiconductor nanostructures, in particular nanowires (NWs), have attracted much attention during the last two decades, becoming a very active field of research $^{1,2}$. Due to their numerous applications, their versatile properties, and the possibility of integrating them into large areas, new techniques have been developed for the creation of flexible electronic and optoelectronic systems based on these nanostructures, which can eventually be manufactured at mass production scale ${ }^{3}$.

Zinc oxide NWs are part of a large family of wide band gap semiconductor nanostructures, including nanoparticles (NPs), nanocombs and nanolayers ${ }^{4}$. Many promising innovative applications in different fields such as photonics ${ }^{5}$, spintronics $^{6}$ and optoelectronics ${ }^{4}$ have been envisaged. $\mathrm{ZnO}$ is a II-VI semiconductor that regularly crystallizes in the hexagonal structure of wurzite, where monoatomic planes of tetrahedrally coordinated $\mathrm{O}^{2-}$ or $\mathrm{Zn}^{2+}$ atoms alternate along 
the axis of hexagonal symmetry (c). This property leads to a preferential growth along this axis, originating elongated nanostructures such as NWs, nanobelts, or nanorods.

Much of the potential of nanotechnology depends on the ability to manipulate atoms during the fabrication process of nanostructures. For $\mathrm{ZnO}$ nanostructures, bottom-up approaches have been applied through various growth methods where the specific morphologies were engineered by controlling growth kinetics or thermodynamic conditions through specific choices of techniques and/or fabrication parameters.

In this review, we focus on specific cost effective and simple techniques for $\mathrm{ZnO}$ nanostructure growth that our group has thoroughly studied in recent years, such as the vapor transport technique, sol-gel, solvothermal and electrophoretic deposition.

\section{Assessment and discussion}

\subsection{Growth of ZnO nanowires}

There are several techniques for the growth of $\mathrm{ZnO}$ nanowires, which can be grossly divided into two categories: vapor phase and liquid phase synthesis. Traditionally, vapor phase techniques have been preferred for electronic and optoelectronic device quality materials, while the liquid phase has been regarded as a group of low-cost methods providing the possibility of fabricating NWs at low temperature. However, recent efforts have shown that the latter can yield to optimum high quality $\mathrm{ZnO} \mathrm{NW}$ materials as well?

\subsubsection{Gas phase methods}

Among gas phase methods, the most popular ones are vapor transport deposition (VTD), molecular beam epitaxy (MBE), pulsed laser deposition (PLD) and atomic layer deposition (ALD).

The VTD technique is one of the simplest methods available to synthesize one-dimensional $\mathrm{ZnO}$ nanostructures and is probably the most widely used because of its relatively low-cost and versatility ${ }^{8}$. Basically, this $\mathrm{ZnO} \mathrm{NW}$ fabrication method consists in transporting $\mathrm{Zn}$ and $\mathrm{O}$ vapors from some source at high temperature, using an inert gas flow, to the zone of a substrate at lower temperature, where vapor atoms condense, deposit and react, forming nanostructures.

Three important points in this technique should be emphasized: 1) the process used to generate source vapors, 2) the transport regime and 3) the mechanism for NW growth on the substrates.

1) Vapor source: $\mathrm{Zn}$ and $\mathrm{O}$ precursors generation can occur in several ways, such as (to name a few):

A) Direct sublimation of $\mathrm{ZnO}$ powder in an inert atmosphere: for this, temperatures of $1400^{\circ} \mathrm{C}$ or higher are required, which is technically difficult and relatively expensive ${ }^{9}$.

B) Sublimation of $\mathrm{Zn}$ metal in an $\mathrm{O}_{2}$ atmosphere: this can be achieved at lower temperatures, approximately $500^{\circ} \mathrm{C}^{9}$, but control of the $\mathrm{Zn}$ to $\mathrm{O}_{2}$ partial pressure ratio $\left(\mathrm{P}_{\mathrm{Zn}} / \mathrm{P}_{\mathrm{O} 2}\right)$ on the substrate may be difficult. This directly affects the ability to control the resulting nanostructure stoichiometry and morphology.

C) The carbothermal reaction, with or without $\mathrm{O}_{2}{ }^{8-12}$, where solid $\mathrm{ZnO}$ and graphite powders are mixed to react at high temperature (between $800^{\circ} \mathrm{C}$ and $1100^{\circ} \mathrm{C}$ ) to reduce the $\mathrm{ZnO}$ into $\mathrm{Zn}$ and $\mathrm{ZnO}_{\mathrm{x}}(\mathrm{x}<1)$ cluster vapors, with the formation of $\mathrm{CO} / \mathrm{CO}_{2}$ as a byproduct. Vapors rich in $\mathrm{Zn}$ then condense on the substrate and react with $\mathrm{O}$ atoms to form the $\mathrm{ZnO}$ nanocrystals, while most of the $\mathrm{CO} / \mathrm{CO}_{2}$ molecules (due to their great stability) are essentially removed by the pumping system ${ }^{13,14}$.

2) Vapor transport: Once $\mathrm{Zn}$ or $\mathrm{ZnO}$ vapors are generated, they are transported within or by the inert or forming gas through essentially two main mechanisms: diffusion and advection ${ }^{11}$. Roughly speaking, and assuming laminar flow, the first mechanism will become dominant at large working pressures within the reactor tube (typically above few Torr) while the second mechanism dominates at lower pressures. At intermediate pressures, transport by both mechanisms may compete. One way to experimentally check the importance of diffusion is searching for growth on substrates placed upstream the source crucible ${ }^{11,12}$. The transport mechanism will determine the velocity and pressure distributions of $\mathrm{Zn}$ precursors along the reactor tube axis, and hence it must be considered when studying growth mechanisms. When advection is dominant, the $\mathrm{Zn}$ vapors mean velocity is directly determined by transport 
gas flow rate and pumping speed. Under these conditions, $\mathrm{Zn}$ precursor pressure $\left(\mathrm{P}_{\mathrm{Zn}}\right)$ will be maximum at a certain distance from the $\mathrm{Zn}$ source and then it will decrease to zero at larger distances ${ }^{11,12,15,16}$. The distance at which $P_{Z n}$ is maximum increases with increasing transport gas flow rate. Other parameters that may locally influence Zn growth precursor concentration and velocity distribution at the growth region are the reactor tube diameter, substrate holder shape, and its position along the tube's cross section ${ }^{17}$.

3) NW growth mechanisms: As the $\mathrm{Zn}, \mathrm{ZnO}_{\mathrm{x}}$ and $\mathrm{O}$ precursors reach the substrate, they react to form the final $\mathrm{ZnO}$ product. Substrates in VTD must support high temperatures (usually, they are placed not too far away from the source, in a colder region within the furnace, where temperature is typically between $500^{\circ} \mathrm{C}$ and $800^{\circ} \mathrm{C}$ ). $\mathrm{NW}$ growth typically requires a metal nanocatalyst seed before fabrication ${ }^{11}$, although catalyst-free substrates have been also reported ${ }^{18}$.

Depending on growth conditions, the application of various mechanisms has been proposed, such as the catalyst-free self-nucleation mechanisms (CFSN), vapor-solid(VS), vapor-liquid-solid (VLS) and combined VLS+VS processes.

The VLS mechanism was originally proposed for $\mathrm{Si} \mathrm{NW}^{19}$ and later reported for $\mathrm{ZnO} \mathrm{NW}$ growth as well ${ }^{8}$. A typical VLS process begins with the absorption of vapor precursor molecules into particles of a catalyst metal previously deposited on the substrate and melted to the liquid state at a high temperature. Adsorbed reactant gases diffuse through the liquid phase of the metal. Then, the drop is supersaturated and nucleation of a precipitate of the source material occurs at the liquid/solid interface between the alloy drop and the substrate. A mark that reveals the VLS process is the presence of catalyst metal NPs on the tips of the fabricated NWs typically observed through electronic microscopy.

The catalyst must be properly selected to make a one-dimensional nanostructure possible and to avoid unwanted solid phases formation in the medium or to avoid metal contamination of the $\mathrm{ZnO}$ NWs. Catalyst species reported for the growth of $\mathrm{ZnO} \mathrm{NWs}$ are $\mathrm{Au}, \mathrm{Ag}, \mathrm{Se}, \mathrm{Cu}$, and $\mathrm{Sn}^{20}$. Also, $\mathrm{Zn}$ has been found to act as a self-catalyst, as a result of the decomposition of the $\mathrm{Zn}$ growth precursor and its subsequent condensation ${ }^{19}$. This is believed to be the principle for $\mathrm{ZnO} \mathrm{NW}$ growth on many catalyst-free substrates (CFSN mechanism). The most used catalyst, however, has been $\mathrm{Au}$, which has the advantage that, when it is alloyed with $\mathrm{Zn}$, its melting temperature turns out to be considerably lower than that of pure $\mathrm{Au}$, due to the $\mathrm{Au}-\mathrm{Zn}$ eutectic temperature of $680^{\circ} \mathrm{C}$ for an $\mathrm{Au}$ rich composition $(66 \%)^{21}$.

Another growth mechanism is VS, which dominates when no intermediate liquid phase for VLS growth is available. In this case, nucleation sites are, in general, structural irregularities at the substrate surface, such as steps, craters, or solid metallic nanoparticles (NPs), whose nanometric roughness results in reactive atomic sites for growth. The VS mechanism was proposed for several $\mathrm{ZnO}$ nanostructure growth experiments on substrates without catalysts ${ }^{11,12,22-24}$. When synthetizing $\mathrm{ZnO} \mathrm{NWs}$ under conditions favoring the VS mechanism, a porous $\mathrm{ZnO}$ wetting layer on the metal-seeded substrate has been often observed below the $\mathrm{ZnO} \mathrm{NWs}{ }^{11,12}$. In this case, the metal catalysts remain below the porous ZnO layer and NWs grow by a VS mechanism on the porous $\mathrm{ZnO}$ layer. The mechanism behind this behavior is believed to be a $2 \mathrm{D}-1 \mathrm{D}$ growth transition to reduce strain after some critical strain has accumulated within the $2 \mathrm{D} \mathrm{ZnO}$ layer ${ }^{11}$. The absence of metal nanoclusters, however, leads to total suppression of any growth on polished crystalline $\mathrm{Si}^{\text {wafers }}{ }^{11}$.

A combined VLS + VS mechanism can also occur on substrates that have catalytic NPs, which remain attached to the substrate during growth ${ }^{22}$ or are immersed in a base layer of $\mathrm{ZnO}$. This phenomenon can occur due to the rapid saturation of the catalyst metal droplets, when a large flow of $\mathrm{ZnO}$ particles is absorbed, generating a new semiconductor nucleation center, from which the nanostructure grows ${ }^{22}$.

Different VTD parameters and their influence on NW morphology and other physical properties have been studied by various authors. When $\mathrm{ZnO} \mathrm{NWs}$ are grown in the advection regime in $\mathrm{O}_{2}$-containing forming gas, the $\mathrm{Zn}$ partial pressure, $\mathrm{P}_{\mathrm{Zn}}$, dependence on the substrate-source distance can be used as a means of changing the $\mathrm{P}_{\mathrm{Zn}} / \mathrm{P}_{\mathrm{O} 2}$ ratio $\left(\mathrm{P}_{\mathrm{O} 2}=\right.$ oxygen partial pressure) to control nanostructure growth morphology ${ }^{11-13}$. While $\mathrm{P}_{\mathrm{O} 2}$ is fixed by the $\mathrm{O}_{2}$ flow rate $\mathrm{Q}_{\mathrm{O} 2}, \mathrm{P}_{\mathrm{Zn}}$ is determined by the transport gas flow rate, $\mathrm{Q}_{\mathrm{Tr}}$, which carries the $\mathrm{Zn}$ vapor from the source to the substrate positions. This important variation of $\mathrm{P}_{\mathrm{Zn}}$ with position has been overlooked in many reports, where only temperature variations with position along the reactor tube axis were considered.

Vega et al. ${ }^{11}$ showed that an increase in the vapor source-substrate distance in the advection regime results in a proportional reduction of NW mean diameters and lengths by more than an order of magnitude (from 800 to $40 \mathrm{~nm}$ and from 22 to $1 \mu \mathrm{m}$, respectively). This was explained as an effect of the reduction of the $\mathrm{Zn}$ supersaturation with increasing distance from the $\mathrm{Zn}$ source.

It has been shown that $\mathrm{ZnO}$ NWs can grow on carbon-based substrates without any metal catalyst $\mathrm{t}^{11,17,25}$. Furthermore, NWs grow directly from the graphite surface without the presence of any wetting $\mathrm{ZnO}$ layer ${ }^{11,17}$. The $\mathrm{ZnO} / \mathrm{C}$ 
system is particularly interesting for field emission applications. $\mathrm{In}^{25}$, the growth of NWs on amorphous carbon substrates was reported and analyzed, and explained in terms of a VS mechanism favored by the immiscibility between $\mathrm{ZnO}$ and $\mathrm{C}$. According to the authors, this immiscibility promotes $\mathrm{NW}$ - as opposed to film - growth to reduce the $\mathrm{ZnO} / \mathrm{C}$ interface area to minimize interface energy.

\subsubsection{Liquid phase synthesis methods}

$\mathrm{ZnO}$ nanostructures can also be obtained through sol-gel ${ }^{26,27}$, hydrothermal or solvothermal synthesis ${ }^{28}$, co-precipitation, electrophoretic deposition ${ }^{29}$, and other liquid phase synthesis techniques. The various advantages offered by these synthetic routes confer them high industrial as well as scientific interest, such as reduction of synthesis temperature and larger yields with respect to vapor deposition methods, and the possibility of implementing scalable processes with better controllability and lower costs. Furthermore, the low synthesis temperature used allows obtaining new metastable phases and materials that would not be feasible using high-temperature fabrication processes ${ }^{28}$, hence paving the way for the exploration of new technological applications.

\section{Sol-gel}

Sol-gel synthesis is among the most popular routes for $\mathrm{ZnO}$ synthesis due to its low cost and possibility to operate at temperatures as low as $150^{\circ} \mathrm{C}$. In sol-gel, molecular precursors are transformed on a stable condensed oxide network through multiple stages - in the first step, the formation of a stable sol precursor through hydrolysis and polymerization occurs, followed by condensation through dehydration, nucleation and growth. The highest temperature throughout the synthesis process occurs at the annealing process needed for the growth stage; for $\mathrm{ZnO}$, an annealing temperature as low as $150^{\circ} \mathrm{C}$ has been reported ${ }^{30}$.

Several parameters affect the growth and orientation of sol-gel synthesized nanostructured $\mathrm{ZnO}$ films - the main ones are type of chelating agent and drying temperature ${ }^{31,32}$. Marin et al. synthesized $\mathrm{ZnO}$ on $\mathrm{SiO}_{2} / \mathrm{Si}$ substrates using the solgel technique with diethanolamine (DEA) as chelating agent and annealing at $600^{\circ} \mathrm{C}$ in an $\mathrm{Ar} / \mathrm{O}_{2}$ atmosphere ${ }^{31,32}$. Contrary to what is commonly found when methanolamine (MEA) is used as chelating agent (for which oriented growth along the c-direction of wurtzite occurs only when subjecting samples to high drying temperature at the condensation stage ${ }^{33}$ ), for DEA such a preferred orientation is observed at low temperature $\left(150^{\circ} \mathrm{C}\right)$ and lost at larger temperature $\left(300^{\circ} \mathrm{C}\right)^{32}$. This result emphasizes the important role of the chelating agent during condensation and polymerization in determining the final $\mathrm{ZnO}$ film texture.

The sol-gel technique also allows the relatively easy fabrication of $\mathrm{ZnO}$ alloys. $\mathrm{In}^{34}$, nanostructured $\mathrm{Zn}_{\mathrm{x}} \mathrm{Ni}_{1-\mathrm{x}} \mathrm{O}$ films $(0<\mathrm{x}<0.2)$ were fabricated using DEA as chelating agent. Since a drying temperature of $300^{\circ} \mathrm{C}$ was used, samples for $\mathrm{x}=0$ (pure $\mathrm{ZnO}$ ) did not show any preferred orientation. Interestingly, the incorporation of Ni was found to promote strong preferential orientation along the $\mathrm{c}$-direction of the wurtzite structure. The experiments showed that for low $\mathrm{x}$ values $(\mathrm{x}$ $<0.1), \mathrm{Ni}^{2+}$ ions were incorporated into the $\mathrm{ZnO}$ lattice substitutionally. This was evidenced by a reduction of the lattice parameter, the observation of oxidized $\mathrm{Ni}$ by X-ray photoelectrons spectroscopy and the absence of the $\mathrm{NiO}$ phase in diffraction patterns ${ }^{34}$.

Typically, the sol-gel method is used for the fabrication of nanocrystalline thin films on substrates, or it may also be employed to obtain nanostructured powders. In contrast, the growth of $\mathrm{ZnO}$ NWs (or nanorods) has been rarely reported, mainly due to the nature of the sol formation process and subsequent gelification. During these stages, nucleation centers are formed within a homogeneous pseudo-polymeric net, and they remain evenly dispersed therein, with no evident mechanism capable of imposing anisotropic growth along any given crystalline direction. However, some reports on $\mathrm{ZnO}$ nanorod growth through sol-gel can be found in the literature ${ }^{30,31}$, albeit this was achieved during the annealing stage of initially fabricated $\mathrm{ZnO}$ thin films through a mechanism that involved surface diffusion of $\mathrm{Zn}$ atoms in a solid-solid process $^{30}$. When growing from solution, the fabrication of $\mathrm{ZnO}$ NWs and nanotubes using alumina templates has been reported $^{32}$, however this technique is complicated due to the high viscosity of colloids used in the sol-gel technique, which hinders their penetration into template pores.

\section{Solvothermal}

In recent years, the interest in $\mathrm{ZnO}$ nanostructure synthesis by solvothermal routes has increased considerably, mainly motivated by i) the possibility of easily attaining different morphologies through the modification of alkaline agent or solvent, ii) the very low temperature of synthesis, usually between 90 to $150^{\circ} \mathrm{C}$, iii) easy doping processes and iv) the possibility of growing different $\mathrm{ZnO}$ arrangements on substrates. 
The synthesis procedure involves the reaction between a metal precursor with an alkaline agent solubilized in a suitable solvent, which can be either water or organic; the reaction occurs in a polytetrafluoroethylene (PTFE) vessel, which is put inside a stainless steel autoclave.

As for the morphology and its relation with the alkaline agent, synthesis of nanostructured $\mathrm{ZnO}$ using several kinds of alkaline agents have been reported, including alkali hydroxides $(\mathrm{NaOH}$ and $\mathrm{KOH})$, ammonia hydroxide $\left(\mathrm{NH}_{4} \mathrm{OH}\right)$, ethanolamine family reagents, and hexamethylenetetramine (MHTA), among others.

It has been demonstrated that the use of alkaline agents from the ethanolamine family, when water is used as the solvent, leads to the formation of $\mathrm{ZnO}$ microspheres resulting from $\mathrm{ZnO}$ nanoparticles agglomeration ${ }^{28,33}$, see Fig. 1(a). Experiments with different diethanolamine (DEA) concentrations indicated that DEA plays a multiple role during the synthesis of such microspheres, including precursor stabilization through the formation a stable colloidal phase, providing a growth medium at alkaline $\mathrm{pH}$ for the_formation of basic $\mathrm{ZnO}$ precursors, and the control of the morphology and nanoparticle agglomeration ${ }^{28}$. On the other hand, when HMTA is used as alkaline agent in presence of water, ZnO NWs are obtained instead of nanoparticles or microspheres ${ }^{34}$, see Figures $1(\mathrm{~b}, \mathrm{c})$.

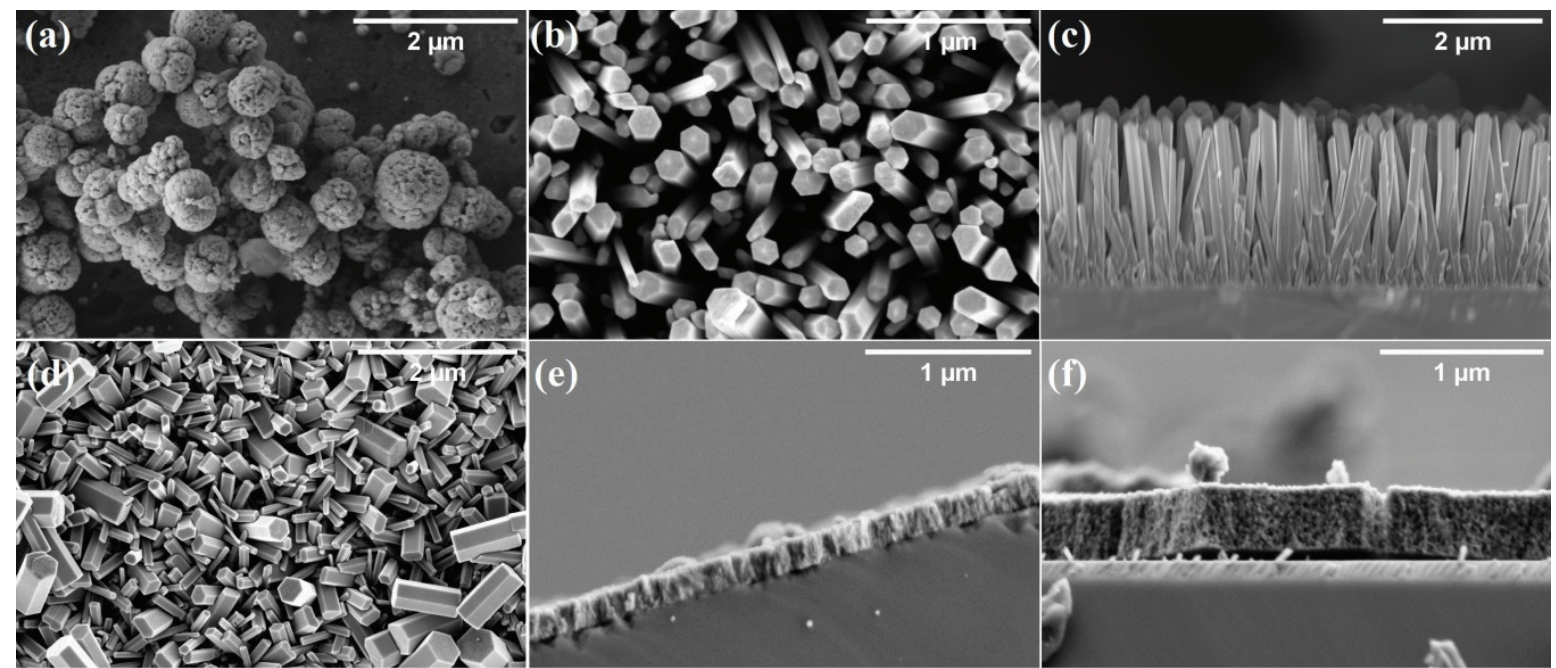

Figure 1. (a) Microspheres obtained with DEA/water; (b, c) top and lateral view of nanowires obtained with HMTA/ water respectively; (d) nano and microprism obtained with HMTA and water:methanol 50:50; (e) columnar thin film obtained with DEA/water; (f) microporous thin film obtained with HMTA/methanol.

As mentioned before, the solvothermal synthesis allows obtaining different arrangements of $\mathrm{ZnO}$ on a substrate, including oriented $\mathrm{ZnO} \mathrm{NWs}, \mathrm{ZnO}$ nano/microprisms and nanostructured films, just by changing either the alkaline agent or the solvent ${ }^{34}$. Thus, with water as solvent, HMTA leads to oriented NWs, while DEA results in a compact columnar nanostructured film ${ }^{28,34}$. Synthesis with alcohols as solvents using DEA also results in compact columnar films, but for HMTA in alcoholic media, a micropourous film formed by an assemble of NPs instead of NWs is obtained, see Fig. 1(d-f).

The mechanism behind this shape-control with HMTA is currently under discussion. Two main hypotheses have been proposed: i) HMTA is absorbed on non-polar surfaces of the growing $\mathrm{ZnO}$ and acts as capping agent, promoting the anisotropic growth along the polar direction and ii) the solubilization and heating of HMTA in water produces its decomposition to formaldehyde and ammonia, and the ammonia can be hydrolyzed to produce $\mathrm{OH}^{-35}$; $\mathrm{HMTA}$ acts as $\mathrm{pH}$ buffer that releases $\mathrm{OH}^{-}$ions slowly to the reactive media, hence promoting a very low $\mathrm{ZnO}$ growth rate resembling thermodynamic quasi-equilibrium conditions. In this case, the anisotropic growth arises from the minimization of the surface area on the polar faces, whose surface energy is larger than that of non-polar faces ${ }^{36}$.

Regarding the first hypothesis, it has been reported that nanorod synthesis can also be carried out by using $\mathrm{NH}_{4} \mathrm{OH}_{\text {or }}$ adding metallic cations to the solution ${ }^{37,38}$, showing that the presence of HMTA or another particular capping agent is not a necessary condition. In addition, the growth of microporous thin films using methanol as solvent, even in presence of HMTA, demonstrates that HMTA by itself does not promote the anisotropic growth that results in $\mathrm{ZnO}^{\mathrm{NWs}}{ }^{34}$.

Recently observed changes in $\mathrm{ZnO}$ nanorod morphology induced by varying HMTA concentration ${ }^{39}$ and temperature ${ }^{40}$ (using water as solvent) indicate that the key to obtain $\mathrm{ZnO}$ nanorods is related to the concentration of $\mathrm{OH}^{-}$ions in the 
reactive medium. When $\mathrm{OH}^{-}$concentration is low, nanorod growth is promoted. When it increases, other morphologies appear. These findings agree with the hypothesis that the synthesis of $\mathrm{ZnO}$ nanorods is controlled by the slow release of $\mathrm{OH}^{-}$rather than by the presence of capping agents on non-polar $\mathrm{ZnO}$ faces.

Less studied, but not less interesting, is the relationship between the structure of intermediate compounds in the synthesis and the final morphology of the synthesized $\mathrm{ZnO}$ products. Since the composition of such intermediate compounds could be related to the composition of the reactive medium, they are expected to correlate with $\mathrm{OH}^{-}$concentration, which in turn is fixed by alkaline agent concentration. Hence, a current challenge in solvothermal synthesis is designing experiments or autoclaves aimed at studying in-situ the initial stages of nanomaterial synthesis in general and $\mathrm{ZnO}$ in particular. Some such experiments have already been designed and carried out ${ }^{41,42}$. Of special interest are the compositions of the intermediate compounds, as well as their morphological and structural properties. A detailed study of these could provide valuable information in efforts to unveil the mechanism controlling the morphology, among other physical properties, of solvothermal synthesized nanomaterials.

\section{Photoluminescence}

Photoluminescence (PL) is one of the most widely studied characteristics of $\mathrm{ZnO}$ because it is one of the properties that lead to promising technological applications such as LED and laser, in addition to providing valuable partial information on the defect structure and bandgap in the $\mathrm{ZnO}$ nanostructure ${ }^{11-13,17,18,24}$. A PL spectrum from a $\mathrm{ZnO}$ sample excited with larger than bandgap energy photons (usually in the UV) typically exhibits two bands: one in the near-UV (at $\sim 3.2 \mathrm{eV}$ ) corresponding to near band-edge (NBE) electron-hole recombination processes ("NBE band"), and a broader one in the visible due to luminescent defect centers with states in the $\mathrm{ZnO}$ bandgap ("defect band"). The reader should bear in mind, however, that there is no consensus about a specific defect type responsible for the defect band. For instance, a component centered at $\sim 2.06 \mathrm{eV}$ (yellow emission) has been associated with interstitial oxygen defects but also with oxygen vacan$\operatorname{cies}^{18}$. For the component centered at $\sim 2.48 \mathrm{eV}$ (green emission), there is also controversy, since it has been attributed to both oxygen vacancies, zinc vacancies and copper contamination ${ }^{18,43}$. Given its relatively large width, the defect band most probably contains contributions from different point defects and defect configurations. Conversely, different point defects may have electronic states at similar energies within the bandgap, thus giving overlapping contributions to the defect PL band.

Hence, it may be expected that PL spectra are very sensitive to the fabrication process. Indeed, in the ZnO nanostructures obtained by high temperature methods (solid state reactions, VTD, sputtering, etc.), the defect band is usually dominated by the green component ${ }^{11-13,17,18,24}$, while in those synthesized through chemical methods (sol-gel, co-precipitation, solvothermal synthesis, etc.), the yellow component predominates ${ }^{28}$.

Let us first discuss the PL from $\mathrm{ZnO}$ nano and microstructures synthesized by solvothermal techniques. When DEA was used as alkaline agent, a time evolution of the PL spectrum while the samples were continuously excited with laser radiation in the UV $(3.81 \mathrm{eV})$ was observed ${ }^{28}$. The defect band in the visible increased and, concomitantly, the NBE band in the UV decreased with irradiation time, see Fig. 2. This PL dependence on irradiation time disappeared, however, when samples were annealed at $900^{\circ} \mathrm{C}$ for $1 \mathrm{~h}$ in air ${ }^{28}$. The fact that the PL could be stabilized both thermally and by prolonged UV illumination led authors to propose that the observed PL behavior was associated with structural metastable configurations that resulted from the low growth temperature ${ }^{28}$.

The PL from VTD ZnO NWs is discussed in Section 2.2.

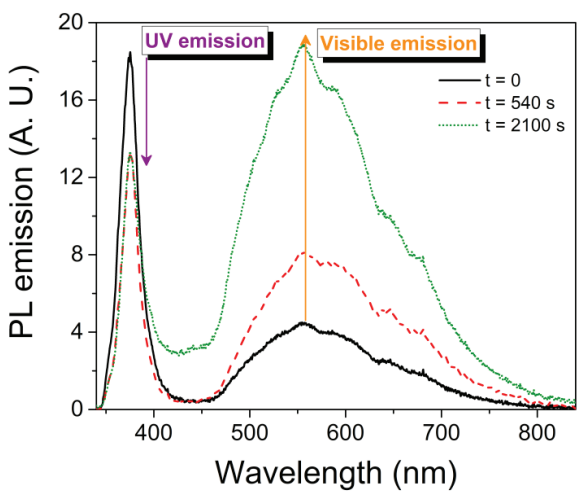

Figure 2. Evolution of the photoluminescence spectrum as function of the excitation time for microspheres obtained with DEA/water. The legend indicates the excitation times at which each spectrum was acquired. From [28], copyright IOP. 
In addition to the elimination of PL metastability, the annealing treatment also was found to induce enhancement of the yellow emission and reduction of the NBE intensity in the UV. The fact that the yellow component dominates the visible emission in the as-grown samples as well as in the annealed samples, in addition to the yellow band increase at the expense of the UV emission (see Fig. 3), suggests that these samples are in a metastable state characterized by a lower than equilibrium defect density, which increases towards its higher equilibrium value by thermal annealing or by laser irradiation $^{28}$.
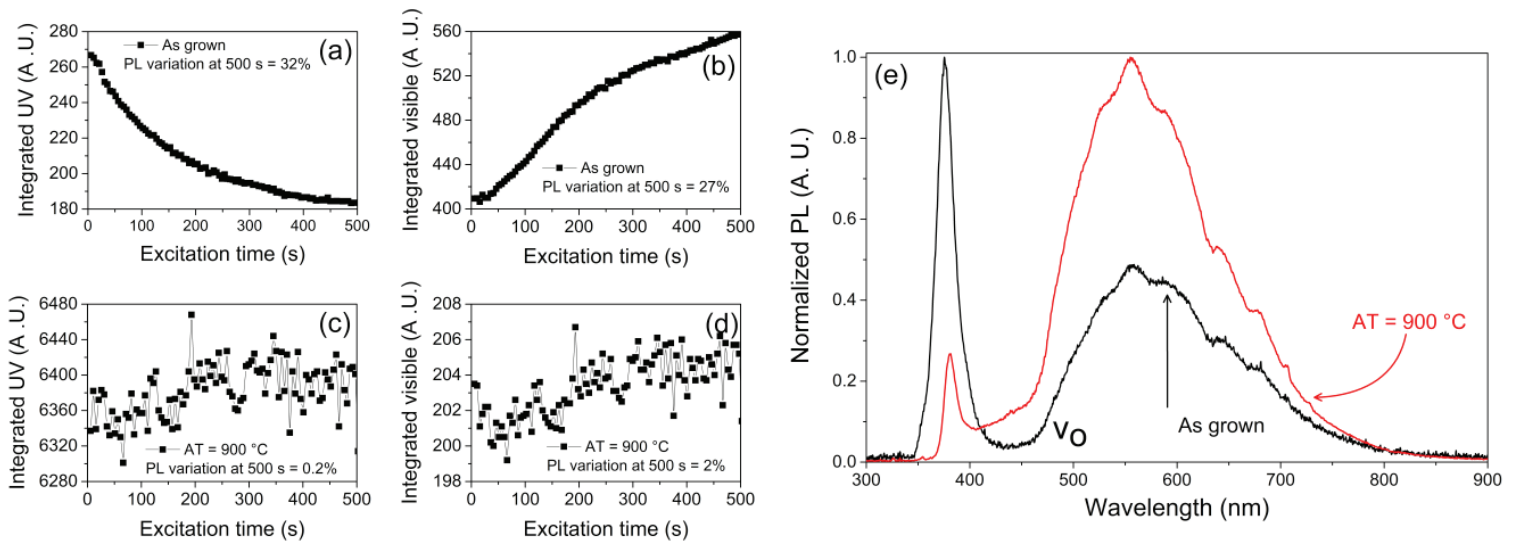

Figure 3. PL evolution for microspheres obtained with DEA/water after annealing at $900^{\circ} \mathrm{C}$ in air. (a, b) integrated emission intensity from the as-grown sample, (c, d) integrated emission intensity from the sample annealed at $900^{\circ} \mathrm{C}$ for $1 \mathrm{~h}$. (e) PL spectra for the as-grown (black) and annealed (red) samples. From ${ }^{28}$, copyright IOP.

\section{Electrophoretic deposition technique}

In the electrophoretic deposition (EPD) technique, charged particles suspended in a liquid move under the action of an electric field through a process known as electrophoresis ${ }^{44,45}$. The electric field is usually produced by a two-electrode system immersed in the liquid suspension, so that charged particles are collected on the oppositely charged electrode to form a deposit. If a stable colloidal suspension with sufficiently low particle content $(<10 \mathrm{~g} / \mathrm{L})$ is used $\mathrm{d}^{46}$, then the particles are sufficiently separated from each other and arrive individually at the electrode. Hence, by conveniently attaching a substrate to this electrode in such conditions, deposits with excellent particle packing uniformity can be obtained. By changing the colloidal suspension, combined depositions of different types of materials can be obtained on the substrate. Materials deposited by EPD include oxides, nitrides, semiconductors, carbides, cermet, bioactive glasses, organic materials, living cells, and others ${ }^{44,45,47}$.

EPD has been recognized as one of the most versatile techniques for particle processing due to the wide variety of size ranges to which it can be applied (from micrometric to nanometric size ${ }^{47,48}$ ). Nanoparticle EPD was first used by Giersig et al. $^{49}$ to prepare ordered monolayers of gold nanoparticles. One of the advantages of EPD over other methods lies on it being a technique based on particles, whose stoichiometry can be controlled during their production stage and, therefore, is directly transferred to the deposit ${ }^{50}$. The characteristics of materials deposited via EPD are influenced as much by parameters related to the colloidal suspension (zeta potential, electrophoretic mobility, $\mathrm{pH}$, conductivity, viscosity, and others) as by physical parameters related to the deposition (working electrode type, substrate material, applied voltage, separation between electrodes, current intensity, deposition time, and others).

The EPD method is an interesting option because it can be used to deposit materials on objects of several shapes and geometrically complicated configurations ${ }^{45,48,51}$. As most wet chemistry methods, EPD does not demand costly or sophisticated equipment. EPD constitutes a low energy consumption, eco-friendly and easily scalable method, which translates as an enormous advantage for its application in the development of low-cost nanotechnology devices.

In this context, the number of publications on electrophoretic deposition of $\mathrm{ZnO}$ has been exponentially increasing in the past few years. These cover different topics of the EPD process, such as electrokinetic phenomena, particle stabilization and surface charge, or the use of templates, as well as growth and applications of EPD $\mathrm{ZnO}$ thin films.

Experimental results using EPD show that the morphology and quality obtained in the deposition are strongly dependent on the substrate type used ${ }^{44,45,47}$. Substrate conductivity and surface morphology are critical parameters that determine deposit quality. For instance, several authors claim that a low conductivity substrate leads to a non-uniform film and slow deposition rates ${ }^{45,48}$. 
Table I shows a selected summary of published data on EPD ZnO fabrication; substrates, colloidal suspensions and main EPD process parameters used, as well as resulting morphologies, are listed.

Table I. Summary of results from the literature on EPD ZnO. In all cases parallel electrodes were used, measurements were performed under room conditions and the deposited material was $\mathrm{ZnO}$.

\begin{tabular}{|c|c|c|c|c|c|c|c|}
\hline Electrode & $\begin{array}{c}\text { Substrate } \\
\text { (deposition } \\
\text { electrode) }\end{array}$ & $\begin{array}{c}\text { Liquid medium } \\
\text { ZnO concentration and } \mathrm{ZnO} \text { average } \\
\text { diameter }\end{array}$ & $\begin{array}{l}\text { Chemical additives } \\
\text { used for stablil- } \\
\text { ization and binder } \\
\text { agent }\end{array}$ & $\begin{array}{c}\text { Process parameters } \\
\mathbf{V}, \Delta \mathbf{L}, \Delta \mathbf{t}\end{array}$ & EPD type & $\begin{array}{l}\text { Deposition } \\
\text { morphology }\end{array}$ & Reference \\
\hline $\begin{array}{l}\text { Stainless } \\
\text { steel }\end{array}$ & $\begin{array}{l}\text { Tin oxide } \\
\text { coated glass }\end{array}$ & $\begin{array}{c}0.004 \mathrm{M} \\
\mathrm{ZnO} \text { colloidal suspension in } \\
\text { 2-Propanol } \\
\text { average diam. } \approx 5 \mathrm{~nm} \\
\text { Bahnemann }[67]\end{array}$ & $\begin{array}{l}\text { No chemical } \\
\text { additives }\end{array}$ & $\begin{array}{l}\approx 10^{2} \mathrm{~V} \\
2 \mathrm{~cm} \\
15 \mathrm{~min}\end{array}$ & $\begin{array}{l}\mathrm{I}=\text { const. } \\
10 \mathrm{~mA}\end{array}$ & Thin Film & $\begin{array}{l}\text { Wong and } \\
\text { Searson [52] }\end{array}$ \\
\hline $\begin{array}{l}\text { Stainless } \\
\text { steel }\end{array}$ & $\begin{array}{l}\text { Tin oxide } \\
\text { coated glass }\end{array}$ & $\begin{array}{c}0.004 \mathrm{M} \\
\mathrm{ZnO} \text { colloidal suspension in } \\
\text { 2-Propanol } \\
\text { average diam. } \approx 5 \mathrm{~nm} \\
\text { Bahnemann [67] }\end{array}$ & $\begin{array}{l}\text { No chemical } \\
\text { additives }\end{array}$ & $\begin{array}{l}\approx 10^{2} \mathrm{~V} \\
2 \mathrm{~cm} \\
1 \mathrm{~h}\end{array}$ & $\begin{array}{c}\mathrm{I}=\text { const. } \\
10 \mathrm{~mA}\end{array}$ & Thin Film & $\begin{array}{l}\text { Wong and } \\
\text { Searson [53] }\end{array}$ \\
\hline $\mathrm{Pt}$ & $\begin{array}{l}\text { AAM } 200 \mathrm{~nm} \text { pore } \\
\text { diameter } \\
\text { attached to } \mathrm{Cu} \text { foil }\end{array}$ & $\begin{array}{l}\mathrm{ZnO} \text { colloidal suspension in } \\
\text { 2-Propanol } \\
\text { average diam. } \approx 5 \mathrm{~nm} \\
\text { Bahnemann }[67]\end{array}$ & $\begin{array}{l}\text { Binder agent: } \\
\mathrm{Zn}\left(\mathrm{NO}_{3}\right)_{2} \cdot 6 \mathrm{H}_{2} \mathrm{O}\end{array}$ & $\begin{array}{l}10-30 \mathrm{~V} \\
60-400 \mathrm{~V} \\
2 \mathrm{~cm} \\
5-25 \mathrm{~min}\end{array}$ & $\mathrm{~V}=$ const. & $\begin{array}{l}\text { Nanofibrils } \\
\text { Nanotubules } \\
\text { In AAM } \\
\text { chanels }\end{array}$ & Wang et al. [54] \\
\hline $\mathrm{Pt}$ & $\begin{array}{l}\text { AAM } 200 \mathrm{~nm} \\
\text { pore diameter, } \\
\text { Au one side coated } \\
\text { attached to } \mathrm{Cu} \text { foil }\end{array}$ & $\begin{array}{l}\mathrm{ZnO} \text { colloidal suspension in } \\
\text { 2-Propanol } \\
\text { average diam. } \approx 5 \mathrm{~nm} \\
\text { Bahnemann }[67]\end{array}$ & $\begin{array}{l}\text { Binder agent: } \\
\mathrm{Zn}\left(\mathrm{NO}_{3}\right)_{2} \cdot 6 \mathrm{H}_{2} \mathrm{O}\end{array}$ & $\begin{array}{l}10-30 \mathrm{~V} \\
60-400 \mathrm{~V} \\
2 \mathrm{~cm} \\
5-25 \mathrm{~min}\end{array}$ & $\mathrm{~V}=$ const. & $\begin{array}{l}\text { Nanofibrils } \\
\text { Nanotubules } \\
\text { In AAM } \\
\text { chanels }\end{array}$ & $\begin{array}{l}\text { Wang et al. } \\
{[55,56]}\end{array}$ \\
\hline $\mathrm{Pt}$ & $\mathrm{Cu}$ foil & $\begin{array}{l}\mathrm{ZnO} \text { colloidal suspension in } \\
\text { 2-Propanol } \\
\text { average diam. } \approx 5 \mathrm{~nm} \\
\text { Bahnemann }[67]\end{array}$ & $\begin{array}{l}\text { Binder agent: } \\
\mathrm{Zn}\left(\mathrm{NO}_{3}\right)_{2} \cdot 6 \mathrm{H}_{2} \mathrm{O}\end{array}$ & $\begin{array}{l}20-100 \mathrm{~V} \\
2 \mathrm{~cm} \\
30-1500 \mathrm{~s}\end{array}$ & $\mathrm{~V}=$ const. & Uniform films & Wang et al. [57] \\
\hline $\mathrm{Cu}$ & $\begin{array}{l}\text { Etched n-type Si substrates } \\
\text { uncovered/covered with a } \\
\text { patterned, developed resist } \\
\text { attached to a Cu electrode } \\
\text { with In-Ga eutectic }\end{array}$ & $\begin{array}{c}1: 5 \mathrm{EtOH} / \mathrm{CHCl}_{3} \text { mixture, } \\
\mathrm{ZnO} \text { concentrations } \\
10-40 \mu \mathrm{M}\end{array}$ & $\begin{array}{l}\text { No chemical } \\
\text { additives }\end{array}$ & $\begin{array}{l}20-100 \mathrm{~V} \\
1-3 \mathrm{~cm} \\
1 \mathrm{~s}-60 \mathrm{~min}\end{array}$ & $\mathrm{~V}=$ const. & $\begin{array}{l}\text { Films with } \\
\text { different } \\
\text { thickness }\end{array}$ & $\begin{array}{l}\text { Lommens et } \\
\text { al. [58] }\end{array}$ \\
\hline $\mathrm{Pt}$ & $\begin{array}{l}\text { Conductive ITO-glass } \\
\text { substrate with } \\
\text { deposited colloidal crystal }\end{array}$ & $\begin{array}{l}\mathrm{ZnO} \text { colloidal suspension in } \\
\text { 2-Propanol } \\
\text { average diam. } \approx 5 \mathrm{~nm} \\
\text { Bahnemann }[67]\end{array}$ & $\begin{array}{l}\text { No chemical } \\
\text { additives }\end{array}$ & $\begin{array}{l}2.5-25 \mathrm{~V} \\
2 \mathrm{~cm} \\
5 \mathrm{~min}\end{array}$ & $\mathrm{~V}=$ const. & $\begin{array}{l}\text { High-quality } \\
\mathrm{ZnO} \text { inverse } \\
\text { opal }\end{array}$ & Chung et al. [59] \\
\hline $\mathrm{Pt}$ & ITO conductive glass & $\begin{array}{l}\mathrm{ZnO} \text { colloidal suspension in } \\
\text { 2-Propanol } \\
\text { average diam. } \approx 5 \mathrm{~nm} \\
\text { Bahnemann }[67]\end{array}$ & $\begin{array}{l}\text { No chemical } \\
\text { additives }\end{array}$ & $\begin{array}{l}50-300 \mathrm{~V} \\
1 \mathrm{~cm} \\
8 \mathrm{~min}\end{array}$ & $\mathrm{~V}=$ const. & Films & Miao et al. [60] \\
\hline $\mathrm{Pt}$ & Stainless Steel and Pt & $10 \mathrm{~g} / \mathrm{L} \mathrm{ZnO}$ suspension in ethanol & $\begin{array}{l}\text { dopamine hydro- } \\
\text { chloride } \\
\text { or alizarin yellow }\end{array}$ & $\begin{array}{l}20-50 \mathrm{~V} \\
1.5 \mathrm{~cm} \\
1-10 \mathrm{~min}\end{array}$ & $\mathrm{~V}=$ const. & Films & Wu et al. [61] \\
\hline $\mathrm{Pt}$ & $\begin{array}{l}\text { Electropolished stainless } \\
\text { steel }\end{array}$ & $\begin{array}{c}\mathrm{g} / \mathrm{L} \text { and } \\
1 \mathrm{~g} / \mathrm{L} \text { aqueous flake-shaped } \\
\mathrm{ZnO} \text { nanopowder suspension } \\
\text { average size } \\
\approx 9.8 \mathrm{~nm}\end{array}$ & $\begin{array}{l}\text { PEI (Polyethylen- } \\
\text { imine) }\end{array}$ & $\begin{array}{c}<5 \mathrm{~V} \\
2 \mathrm{~cm} \\
1-10 \mathrm{~min}\end{array}$ & $\mathrm{I}=$ const. & Films & Verde et al. [50] \\
\hline $\begin{array}{l}\text { Stainless } \\
\text { steel }\end{array}$ & WE43 magnesium alloy & $\begin{array}{c}5 \mathrm{~g} / \mathrm{L} \mathrm{de} \mathrm{ZnO} \text { in } 10^{-3} \mathrm{M} \mathrm{Zn}\left(\mathrm{NO}_{3}\right)_{2} \text { in a } \\
\text { mixture } \\
\text { of } 95 \% \text { vol. anhydrous ethanol and } \\
5 \% \text { vol. deionized water, } \\
\text { average diam. } \approx 50 \mathrm{~nm}\end{array}$ & $\begin{array}{l}\text { No chemical } \\
\text { additives }\end{array}$ & $\begin{array}{l}2.5-4 \mathrm{~V} \\
2 \mathrm{~cm} \\
30-210 \mathrm{~min}\end{array}$ & $\mathrm{~V}=$ const. & Films & Qu et al. [62] \\
\hline $\mathrm{Pt}$ & $\begin{array}{l}\text { Si substrate with } \mathrm{Au} \\
\text { nanoclusters previously } \\
\text { deposited }\end{array}$ & $\begin{array}{l}\mathrm{ZnO} \text { colloidal suspension in } \\
\text { 2-Propanol } \\
\text { average diam. } \approx 5 \mathrm{~nm} \\
\text { Bahnemann }[67]\end{array}$ & $\begin{array}{l}\text { No chemical } \\
\text { additives }\end{array}$ & $\begin{array}{c}30 \mathrm{~V} \\
7 \mathrm{~mm} \\
1 \mathrm{~h}\end{array}$ & $\mathrm{~V}=$ const. & Nanowires & $\begin{array}{c}\text { Sandoval et al. } \\
\text { [29] }\end{array}$ \\
\hline $\mathrm{Pt}$ & B doped Si substrate & $\begin{array}{l}\mathrm{ZnO} \text { colloidal suspension in } \\
\text { 2-Propanol } \\
\text { average diam. } \approx 5 \mathrm{~nm} \\
\text { Bahnemann }[67]\end{array}$ & $\begin{array}{l}\text { No chemical } \\
\text { additives }\end{array}$ & $\begin{array}{l}33 \mathrm{~V} \\
7.5 \mathrm{~mm} \\
1 \mathrm{~h}\end{array}$ & $\mathrm{~V}=$ const. & $\begin{array}{l}\text { Nanowires } \\
\text { bunches }\end{array}$ & $\begin{array}{l}\text { Real et al. [63] } \\
\text { Espíndola et } \\
\text { al. [64] }\end{array}$ \\
\hline
\end{tabular}

EPD is generally used to obtain films, whereas, according to the bibliography, ZnO with other morphologies or aspect ratios have been achieved mainly through templates. Some of the most widely used templates are anodic alumina membranes (AAM) or porous alumina membranes ${ }^{47,65}$. In these publications, two types of $\mathrm{ZnO}$ nanostructure morphologies (fibrils, tubules) and a mix of both, were reported, depending on the voltage-dependent filling characteristics of the AAM. The use of membranes, however, is relatively expensive and difficulties often arise when post-growth elimination of templates is necessary, as is generally the case due to undesired impacts of the membrane on the fabricated composite properties (see, for instance, ref. $^{66}$ ). 
In order to avoid these drawbacks, our research group proposed the use of substrates on which Au nanoclusters had been previously deposited for the growth of ZnO NWs without any membrane templates ${ }^{29}$. Au nanoclusters (15-25 nm) change the morphology of working electrodes and, hence, may promote a concentration of the electric field lines on nanoclusters, thus inducing the preferential deposition of particles on the nanoclusters. Indeed, the metallic character of the nanoclusters should impose new boundary conditions on the electric field lines, leading to their alignment normally to the curved nanocluster surfaces. This would in turn produce a "focusing effect", driving electric field lines away from the uncovered low-conductivity Si substrate and towards the Au nanoclusters. ZnO NPs are electrophoretically transferred from the colloidal suspension to the substrate along the electric field lines, resulting in their columnar packing on Au nanoclusters, giving rise to the observed growth of $\mathrm{ZnO}$ NWs. It should be noted that Au nanoclusters do not affect the band gap energy of $\mathrm{ZnO}$ nanowires as they are not incorporated into $\mathrm{ZnO}$ structure.

EPD deposition was carried out from a low concentration colloidal suspension of $\mathrm{ZnO}$ nanoparticles in 2-propanol, synthesized following the precipitation method reported by Bahnemann et al. ${ }^{67}$. The nanoparticles obtained in the colloidal suspension have an average diameter of $5 \mathrm{~nm}$ with a narrow size distribution, between 4 and $6 \mathrm{~nm}$, which induces a more orderly packing, since similar sized particles tend to pack together, in concordance with Tabellion et al. ${ }^{68}$. The sample obtained showed a large density of $\mathrm{ZnO}$ NWs, with preferential vertical orientation. Their diameters ranged between 20 and $90 \mathrm{~nm}$, and lengths were around $\sim 1.2 \mu \mathrm{m}$. The possibility of growing ZnO NWs at room temperature and without the use of templates by EPD is to be highlighted and should lead to further work to explore controllability of the method and properties of the NWs obtained.

More recently, efforts were directed to attain $\mathrm{ZnO}$ NW growth by EPD without using metallic nanoclusters. Experiments included the use of highly doped Si substrates for improved conductivity and uniformity of the electric field lines close to the substrates. EPD samples grown on boron doped Si substrates without Au nanoclusters showed novel nanostructures consisting of $\mathrm{ZnO} \mathrm{NW}$ bunches ${ }^{63,64}$. Figures $4(\mathrm{a}, \mathrm{b})$ show scanning electron microscopy (SEM) micrographs at different magnifications of the $\mathrm{ZnO}$ nanostructures grown on p-type crystalline Si doped with $\mathrm{B}<100>$ substrates, polished surface high quality, with resistivity (1-10) $\Omega \mathrm{cm}$. Optimum parameters of applied voltage, separation between electrodes and deposition time were $33 \mathrm{~V}, 7.5 \mathrm{~mm}$ and $1 \mathrm{~h}$, respectively. The sample obtained showed a large density of $\mathrm{ZnO} \mathrm{NW}$ bunches, with diameters ranging between 55 and $85 \mathrm{~nm}$, apparent lengths between 330 and $500 \mathrm{~nm}$ and NW bunch diameters around $1 \mu \mathrm{m}$.
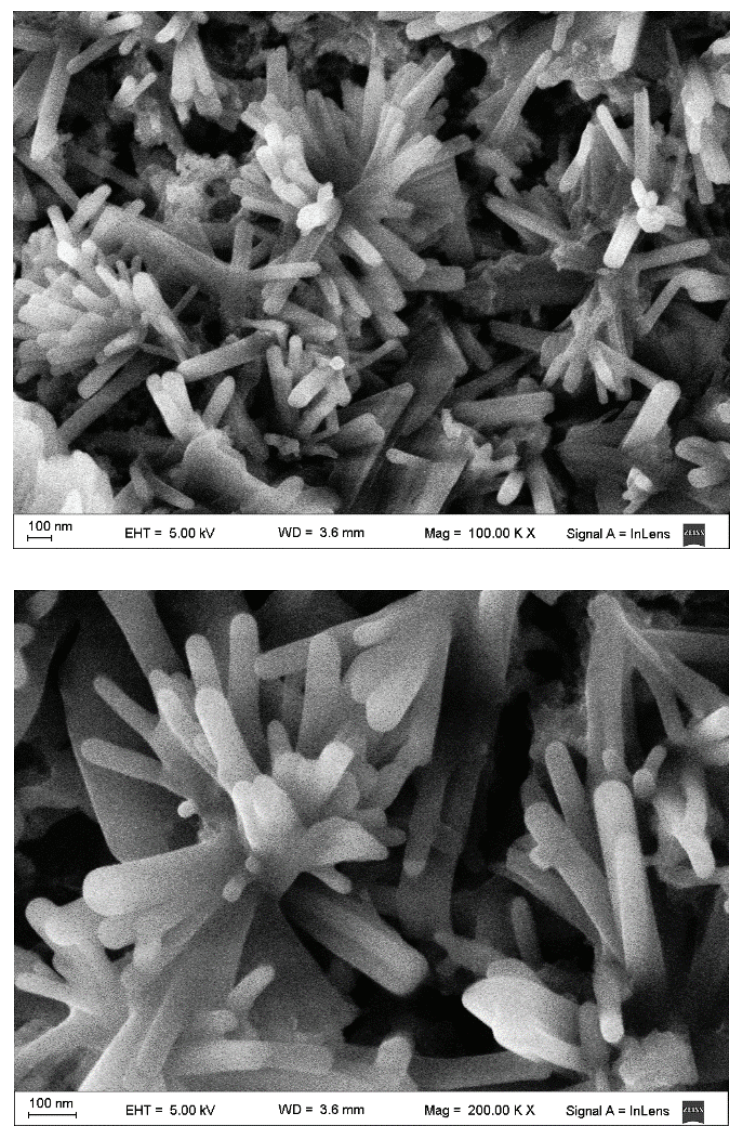

Figure 4. SEM micrographs at different magnifications a) $100 \mathrm{KX}$ and b) $200 \mathrm{KX}$, of $\mathrm{ZnO}$ nanowire bunches, grown on p-type crystalline Si doped with $\mathrm{B}<100>$ substrates, with resistivity $(1-10) \Omega \mathrm{cm}$. Optimum parameters of applied voltage, electrode-substrate separation and deposition time were $33 \mathrm{~V}, 7.5 \mathrm{~mm}$ and $1 \mathrm{~h}$, respectively. 
In the early stages of deposition (at 40 minutes), SEM micrographs show the appearance of a nanoporous film on which NW bunches grow, see Figure $5(\mathrm{a}, \mathrm{b})$. One might think that the formation of these NW bunches comes from preferential centers of growth, whether present in the substrate or in the nanoporous film. According to Besra et al. ${ }^{69}$, particle deposition by EPD on a poor-conducting substrate is made possible through the use of an adequately porous substrate which facilitates availability of electric field near the substrate. The pores, when saturated with the solvent, help establishing a conductive path between the electrical contact and the particles in suspension. Besra found that deposition increases with increasing porosity up to a certain value. For a given applied voltage, there exists a threshold porosity value above which deposition by EPD is possible ${ }^{45}$.
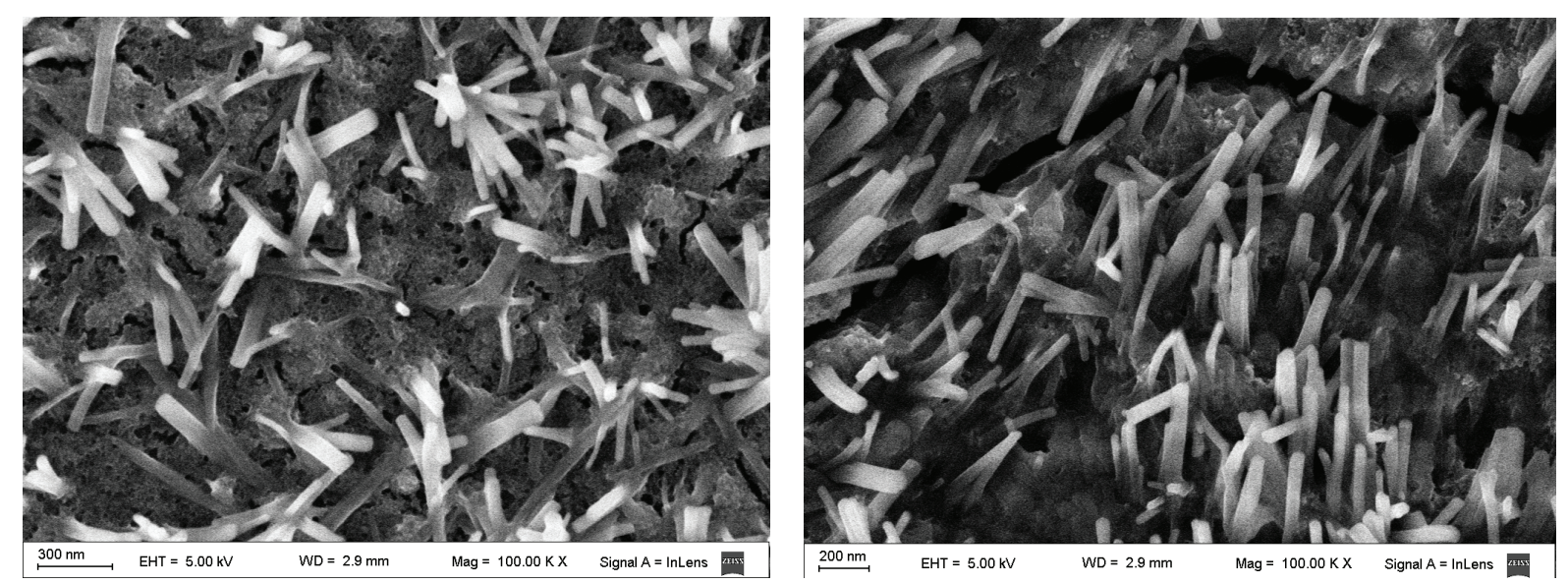

Figure 5. SEM micrographs of $\mathrm{ZnO}$ nanowires grown in the first stages of deposition by EPD, corresponding to two different zones of the same sample ( $\mathrm{a}$ and $\mathrm{b}$ ). It shows the initial appearance of a nanoporous film on which the $\mathrm{ZnO}$ nanowires grow. Parameters of applied voltage, electrode-substrate separation and deposition time were $33 \mathrm{~V}, 7.5 \mathrm{~mm}$ and 40 minutes, respectively. SEM micrographs at $100 \mathrm{KX}$ of magnification.

\subsection{Surface passivation of $\mathrm{ZnO}$ NWs}

Many years of research have shown that the effective surface passivation of $\mathrm{ZnO}$ nanomaterials to neutralize surface electronic and optical effects is crucial for applications in optoelectronics due to the large specific surface area of these nanostructures. For instance, surface trap states shorten carrier lifetimes and are responsible for deep-defect luminescence in the visible ${ }^{24,70}$. Strategies proposed to provide effective passivation have included annealing in forming atmospheres and the deposition of various shell materials, such as $\mathrm{PMMA}^{71}$, polyvinyl-alcohol (PVA) ${ }^{72}$ or polymers ${ }^{73}$. The MgO coating of the $\mathrm{ZnO} \mathrm{NW}$ has been proved to reduce lasing thresholds and enhance excitonic PL ${ }^{24,74-75}$. As $\mathrm{ZnO}, \mathrm{MgO}$ is II-VI wide band-gap oxide; however, since it exhibits a much larger $\mathrm{MgO}$ bandgap than that of $\mathrm{ZnO}(\sim 7.8 \mathrm{eV}$ as compared to $\sim 3.3$ $\mathrm{eV}$ ), a $\mathrm{MgO}$ shell is expected to provide very efficient confining barriers to both electrons and holes within the $\mathrm{ZnO}$ core, which in turn should further favor UV radiative excitonic recombination. Typically, hydrothermal ${ }^{4}$ and electron beam evaporation synthesis ${ }^{78}$ have been used to coat $\mathrm{ZnO} N W s$ with $\mathrm{MgO}$. An attractive method for the fabrication of $\mathrm{ZnO}$ and $\mathrm{ZnO} / \mathrm{MgO}$ core/shell NWs is $\mathrm{VTD}^{75}$.

While the $\mathrm{MgO}$ shell is indeed very useful in improving the UV emission from $\mathrm{ZnO}$ nanostructures and reducing the spurious visible emission due to surface defects, the physical passivation mechanisms behind these improvements remained elusive for many years. Some authors suggested that the $\mathrm{MgO}$ shell physically removes oxygen vacancies or other defects from the $\mathrm{ZnO} \mathrm{NW}$ walls, thus eliminating the recombination channels that compete with the excitonic recombination $^{79}$. Others, inspired by the fact that efficient passivation effects have been achieved using not only $\mathrm{MgO}$, but also polymers and other insulating materials, proposed a model where dielectric screening that could be provided by any dielectric shell was responsible for the beneficial effects observed ${ }^{80}$. Later, a new model was introduced where passivation is not due to elimination of surface states, but a result of mechanical stabilization of the nanosurfaces ${ }^{81}$.

Grinblat et al. ${ }^{24}$ and Vega et al. ${ }^{76}$ studied this problem in $\mathrm{ZnO} / \mathrm{MgO}$ core/shell NWs grown by a two-step VTD technique. Scanning and transmission electron microscopy (SEM and HRTEM) images of the $\mathrm{ZnO}$ and $\mathrm{ZnO} / \mathrm{MgO}$ core/ shell NWs are shown in Fig. 6. A clear correlation between the PL defect/NBE bands ratio and the specific surface area of hierarchical $\mathrm{ZnO}$ nanostructures ${ }^{12}$ had shown previously that most luminescent defects were at the $\mathrm{ZnO}$ surfaces. By analyzing PL temperature dependence on $\mathrm{ZnO} / \mathrm{MgO}$ core/shell $\mathrm{NW}$ samples, it was concluded that the $\mathrm{MgO}$ shell, when grown under the right conditions, led to strong shortening of the excitonic radiative recombination time and to orders of 
magnitude increase of the $\mathrm{UV}$ emission ${ }^{24} \cdot \mathrm{In}^{76}, \mathrm{ZnO} / \mathrm{MgO}$ core/shell $\mathrm{NWs}$ with varying shell widths $(w)$ were grown in an effort to shed light on the passivation mechanism. The PL dependence on $w$ revealed that a thin $\mathrm{MgO}$ shell of a few monolayers was not enough to fully passivate the surface. Instead, a gradual increase (decrease) of the PL intensity for the UV (visible) band with increasing $w$ was observed. Only after a sufficiently thick shell was deposited ( $w \sim 17 \mathrm{~nm})$, optimal passivation was attained ${ }^{76}$. This was explained as the combination of two effects: one related to the elimination of the $\mathrm{ZnO}$ $\mathrm{NW}$ /air interface, which is achieved for the thinnest $\mathrm{MgO}$ shell, and another $w$-dependent effect.

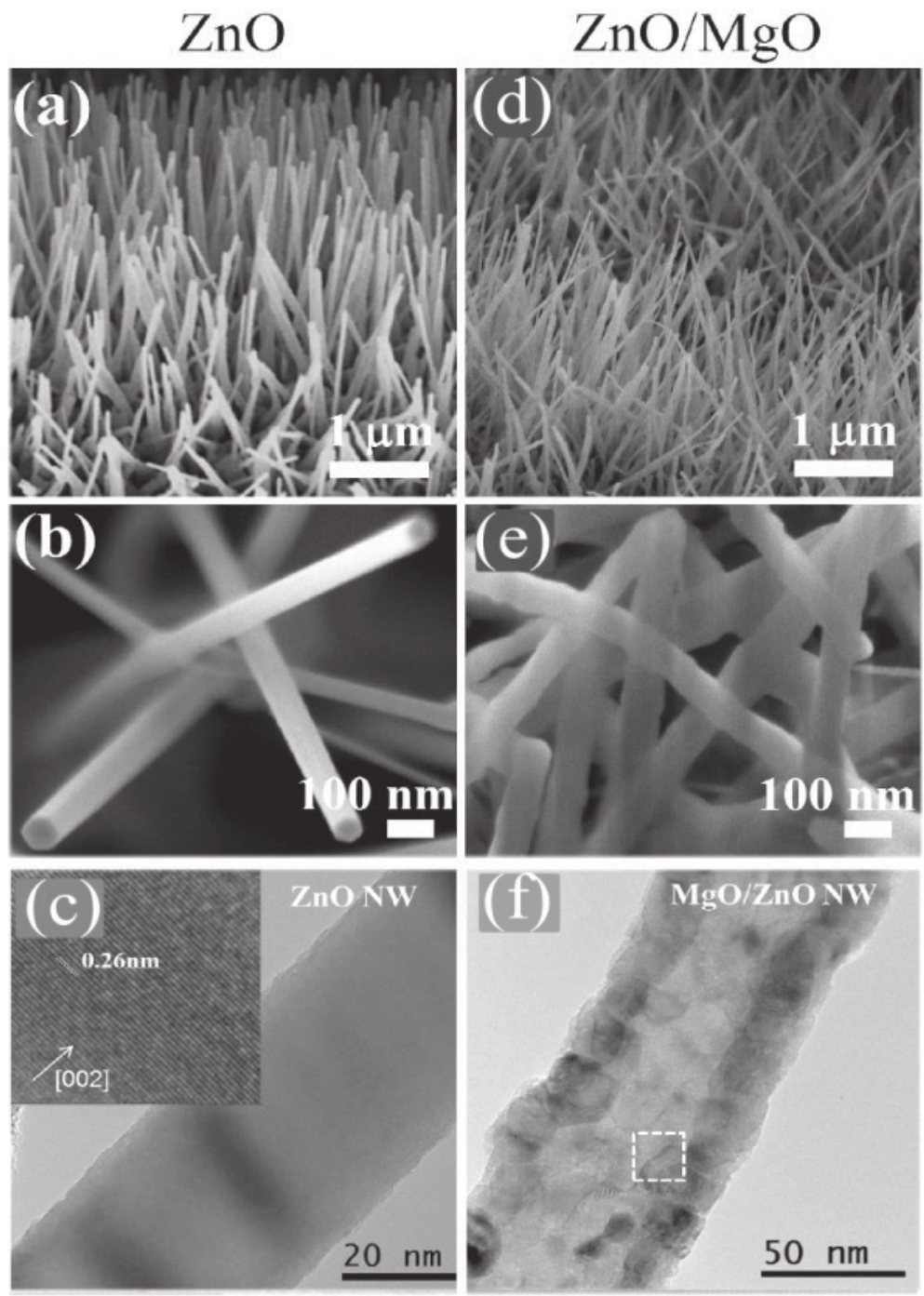

Figure 6. SEM images with different magnifications of a $\mathrm{ZnO} \mathrm{NW}$ sample (a), (b) and of a $\mathrm{ZnO} / \mathrm{MgO}$ core/shell NW sample (d), (e). As observed in (b), the ZnO NWs are highly crystalline, exhibiting hexagonal cross-section expected from wurtzite c-axis alignment. (c) and (f) show HRTEM images of a $\mathrm{ZnO} \mathrm{NW}$ and of a $\mathrm{ZnO} / \mathrm{MgO}$ core/shell NW, respectively. From $^{76}$.

To understand these effects, the excitonic NBE emission band shape dependence on $w$ was carefully studied. The intensities of the first and second longitudinal-optical (LO) phonon replica of the free exciton recombination emission, which dominate the $\mathrm{NBE}$ band from $\mathrm{ZnO}$ at room temperature, changed dramatically with the incorporation of the $\mathrm{MgO}$ shell; see Fig. $7^{76}$. The relative contribution of the second phonon replica was strongly reduced, while the otherwise weak free exciton recombination contribution was intensified by orders of magnitude. This indicated a reduced exciton-phonon coupling probably because the $\mathrm{MgO}$ shell induced reduction of $\mathrm{Zn}$ and $\mathrm{O}$ atoms surface vibrational amplitudes. 


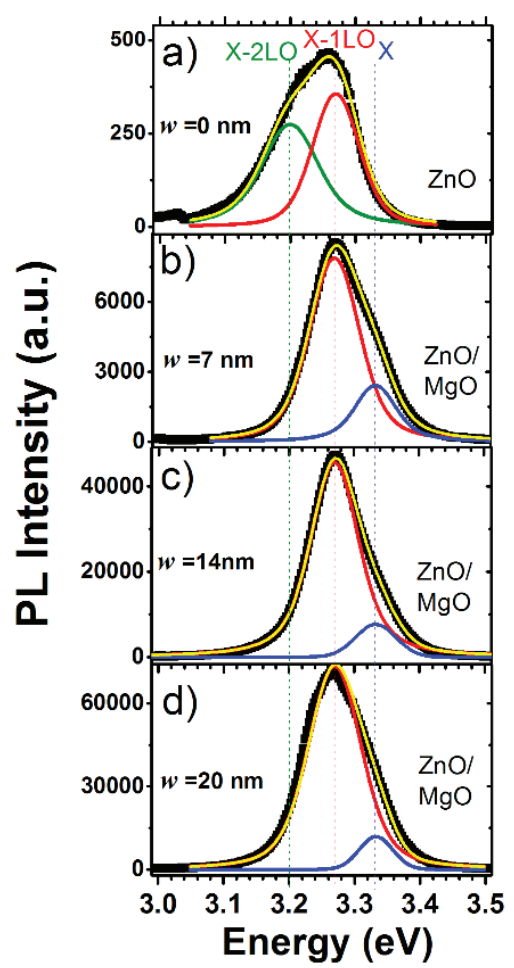

Figure 7. Experimental (black symbols) and fitted (yellow lines) PL spectra from $\mathrm{ZnO}$ (a) and from $\mathrm{ZnO} / \mathrm{MgO}$ core/ shell NW samples (b, c, d), for different MgO shell widths, $w$, in the UV region (NBE band). The components of the fits attributed to the excitonic emission (X) and its phonon replica (X-1LO, X-2LO) are indicated by vertical dashed lines (positions) and by blue, red, and green, respectively. Note the very different vertical scales in (a, b, c, d). From ${ }^{76}$.

The study also found significant strain build-up within the $\mathrm{ZnO}$ core, which increased with increasing $\mathrm{MgO}$ shell width $w$ and correlated with the NBE/defect bands intensity ratio. It was then concluded that the NBE band enhancement and defect band quench in the core/shell NWs involved complex mechanisms that include elimination of adsorbates and mechanical stabilization of the $\mathrm{ZnO} \mathrm{NW}$ interface (which dominate for small $w$ ) and strain build-up (which becomes increasingly important with increasing $w$ ).

\section{Conclusion}

In this review, we have briefly described much of the important work devoted in recent years towards the effective control of the morphology, structure and optical properties of $\mathrm{ZnO}$ nanostructures, with special focus on our own work on $\mathrm{ZnO}$ NWs. Much progress has been achieved in the basic understanding of the main mechanisms involved in VTD, enabling better control and reproducibility of $\mathrm{ZnO} \mathrm{NW}$ growth and properties, such as length, diameter and luminescence. Furthermore, it has been possible to synthetize ZnO NWs under different prevailing mechanisms (such as VLS, VS and VLS+VS), to systematically change the $\mathrm{ZnO}$ nanostructure morphology by changing the $\mathrm{P}_{\mathrm{Zn}} / \mathrm{P}_{\mathrm{O} 2}$ ratio, to synthetize $\mathrm{NWs}$ without metal catalyst, to eliminate the $\mathrm{ZnO}$ layer that grows under advection conditions on various metal catalyzed substrates, and to fabricate $\mathrm{ZnO} / \mathrm{MgO}$ core/shell NWs.

In the quest for novel applications of NWs potential in general, and ZnO NWs in particular, the proposal for their integration into flexible (optoelectronic, electronic, spintronic, photonic or any combination of these) circuits has promoted the development of novel growth methods at low temperatures. The possibility of synthetizing $\mathrm{ZnO}$ NWs at room temperature on at least two types of conveniently preformed substrates by just manipulating colloidal ZnO NPs with electric fields, as in EPD, is very encouraging. Even though understanding of growth mechanisms during sol-gel, solvothermal and EPD techniques has improved substantially as a result of years of research, especially on the role of the solvent and the alkaline agent on the morphology during solvothermal synthesis, it is clear that much work is still needed. In particular, studies on the composition and structure of intermediate products within the complex reactive media in solvothermal synthesis are needed to achieve a better control of the size and defect structure of $\mathrm{ZnO}$ nanostructures deposited at low temperatures on the one hand. PL metastability, on the other hand, deserves greater attention because it shows structural 
metastabilities that, albeit expected for low temperature processing, could be detrimental for real life applications of these nanostructures.

Last but not least, it is clear that after many years of work, a consistent picture of the $\mathrm{ZnO} \mathrm{NW}$ surface passivation mechanism is finally emerging. The main role of the shell is that of a physical barrier that separates the $\mathrm{ZnO} \mathrm{NW}$ walls from atmospheric adsorbates, which otherwise provide detrimental surface states on $\mathrm{ZnO} \mathrm{NW}$ walls. Hence, to a first approximation, this can explain the large enhancements of the UV emission and the quenching of the defect band when NWs are covered with a broad range of shells (from polymers to ceramic oxides). However, other important physical effects (such as strain buildup, mechanical stabilization and confinement) may also occur, which lead to strong changes in PL spectra and may depend on shell thickness. Some of these effects are specific to the shell material, as they depend on the shell electronic, structural and mechanical properties. Future studies will focus on applications of these passivated $\mathrm{ZnO}$ NWs on different devices and the choice of the passivating shell material will certainly depend on each technological platform specific requirements.

\section{References}

[1] Y. Xia, P. Yang, Y. Sun, Y. Wu, B. Mayers, B. Gates, Y. Yin, F. Kim, and H. Yan. One-Dimensional Nanostructures: Synthesis, Characterization, and Applications. Adv. Mater., 15(5):353-389, 2003.

[2] C. Lieber and Z. Wang. Functional Nanowires. MRS Bull., 32(02):99-108, 2007.

[3] X. Wang, C. Summers, and Z. Wang. Large-Scale Hexagonal-Patterned Growth of Aligned ZnO Nanorods for Nano-optoelectronics and Nanosensor Arrays. Nano Lett., 4(3):423-426, 2004.

[4] M. Willander. Zinc Oxide Nanostructures: Advances and Applications. Jenny Stanford Publishing, New York, USA, 2013.

[5] G. Grinblat, M. Rahmani, E. Cortés, M. Caldarola, D. Comedi, S. Maier, and A. Bragas. High Efficiency Second Harmonic Generation from a Single Hybrid ZnO Nanowire/Au Plasmonic Nano-Oligomer. Nano Lett., 14(11):66606665, 2014.

[6] Y. Tian, S. Bakaula, and T. Wu. Oxide Nanowires for Spintronics: Materials and Devices. Nanoscale, 4:1529-1540, 2012.

[7] A. Kołodziejczak-Radzimska and T. Jesionowski. Zinc Oxide-From Synthesis to Application: A Review. Materials, 7(4):2833-2881, 2014.

[8] M. Huang, Y. Wu, H. Feick, N. Tran, E. Weber, and P. Yang. Catalytic Growth of Zinc Oxide Nanowires by Vapor Transport. Adv. Mater., 13(2):113-116, 2001.

[9] Z. Wang. Zinc Oxide Nanostructures: Growth, Properties and Applications. J. Phys. Condens. Matter., 16(25):829858,2004

${ }^{[10]}$ D. Comedi, M. Tirado, C. Zapata, S.P. Heluani, M. Villafuerte, P. Mohseni, and R.R. LaPierre. Randomly Oriented $\mathrm{ZnO}$ Nanowires Grown on Amorphous $\mathrm{SiO}_{2}$ by Metal-Catalized Vapour Deposition. J. Alloys Compd., 495(2):439442,2010 .

${ }^{[11]}$ N.C. Vega, R. Wallar, J. Caram, G. Grinblat, M. Tirado, R.R. LaPierre, and D. Comedi. ZnO Nanowire co-Growth on $\mathrm{SiO}_{2}$ and $\mathrm{C}$ by Carbothermal Reduction and Vapour Advection. Nanotechnology, 23(27):275602, 2012.

${ }^{[12]}$ G. Grinblat, M.G. Capeluto, M. Tirado, A.V. Bragas, and D. Comedi. Hierarchical ZnO nanostructures: Growth Mechanisms and Surface Correlated Photoluminescence. Appl. Phys. Lett., 100:233116, 2012.

${ }^{[13]}$ N.C. Vega, M. Tirado, D. Comedi, A. Rodriguez, T. Rodriguez, G. Hughes, Crm. Grovenor, and F. Audebert. Electrical, Photoelectrical and Morphological Properties of $\mathrm{ZnO}$ Nanofiber Networks Grown on $\mathrm{SiO}_{2}$ and on Si Nanowires. Mater. Res., 16(3):597-602, 2013.

${ }^{[14]}$ M. Biswas, E. Mcglynn, M. Henry, M. McCann, and A. Rafferty. Carbothermal Reduction Vapor Phase Transport Growth of ZnO Nanostructures: Effects of Various Carbon Sources. J. Appl. Phys., 105(9):094306, 2009. 
${ }^{[15]}$ C. Ye, X. Fang, Y. Hao, X. Teng, and L. Zhang. Zinc Oxide Nanostructures: Morphology Derivation and Evolution. J. Phys. Chem. B, 109(42):19758-19765, 2005.

[16] J.H. Choi, J.S. Seo, S.N. Cha, H.J. Kim, S.M. Kim, Y.J. Park, S. Kim, J. Yoo, and J.M. Kim. Effects of Flow Transport of the Ar Carrier on the Synthesis of ZnO Nanowires by Chemical Vapor Deposition. Jpn. J. Appl. Phys., 50(1R):015001, 2011.

[17] E. Tosi. Estudio de Superficies de Nanoestructuras Semiconductoras. PhD Thesis, Universidad Nacional de Tucumán, Argentina (2019).

${ }^{[18]}$ O. Marin, G. Grinblat, A.M. Gennaro, M. Tirado, R.R. Koropecki, and D. Comedi. On the Origin of White Photoluminescence from ZnO Nanocones/Porous Silicon Heterostructures at Room Temperature. Superlattices Microstruct., $79: 29-37,2015$.

[19] R.S. Wagner and W.C. Ellis. Vapor-Liquid-Solid Mechanism of Single Crystal Growth. Appl. Phys. Lett., 4(5):89-90, 1964.

[20] T. Steiner. Semiconductor Nanostructures for Optoelectronics Applications. Semiconductor Materials and Devices Series, Artech House, Inc., USA, 2004.

${ }^{[21]}$ H.S. Liu, K. Ishida, Z.P. Jin, and Y. Du. Thermodynamic Assessment of the Au-Zn Binary System. Intermetallics, 11(10):987-994, 2003.

${ }^{[22]}$ D.S. Kim, R. Scholz, U. Gösele, and M. Zacharias. Gold at the Root or at the Tip of ZnO Nanowires: A Model. Small, 4(10):1615-1619, 2008.

${ }^{[23]}$ G. Zhu, Y. Zhou, S. Wang, R. Yang, Y. Ding, X. Wang, Y. Bando, and Z. Wang. Synthesis of Vertically Aligned Ultra-Long ZnO Nanowires on Heterogeneous Substrates with Catalyst at the Root. Nanotechnology, 23(5):055604, 2012.

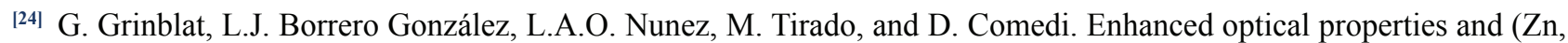
$\mathrm{Mg}$ ) interdiffusion in vapour transport grown $\mathrm{ZnO} / \mathrm{MgO}$ core/shell nanowires. Nanotechnology, 25(3):035705, 2014.

[25] Y.H. Yang, C.X. Wang, B. Wang, N. Xu, and G.W. Yang. ZnO nanowire and amorphous diamond nanocomposites and field emission enhancement. Chem. Phys. Lett., 403(4-6):248-251, 2005.

[26] O. Marin, P. Alastuey, E. Tosi, J. Orive, E. Mosquera, G. Zampieri, S. Suárez, D. Comedi, and M. Tirado. Suppression of the green emission, texturing, solute-atom diffusion and increased electron-phonon coupling induced by Ni in solgel ZnNiO thin films. Appl. Surf. Sci., 456:771-780, 2018.

[27] O. Marin, M. Tirado, N. Budini, E. Mosquera, C. Figueroa, and D. Comedi. Photoluminescence from c-axis oriented $\mathrm{ZnO}$ films synthesized by sol-gel with diethanolamine as chelating agent. Mater. Sci. Semicond. Process., 56:59-65, 2016.

${ }^{[28]}$ V. González, O. Marin, M. Tirado, and D. Comedi. Metastability effects on the photoluminescence of ZnO nano-micro structures grown at low temperature and influence of the precursors on their morphology and structure. Mater. Res. Express. 5:125003, 2018.

${ }^{[29]}$ C. Sandoval, O. Marin, S. Real, D. Comedi, and M. Tirado. Electrophoretic deposition of ZnO nanostructures: Au nanoclusters on Si substrates induce self-assembled nanowire growth. Mater. Sci. Eng. B, 187:21-25, 2014.

${ }^{[30]}$ M.W. Zhu, N. Huang, J. Gong, B. Zhang, Z.J. Wang, C. Sun, and X. Jiang. Growth of ZnO nanorod arrays by solgel method: transition from two-dimensional film to one-dimensional nanostructure. Appl. Phys. A, 103(1):159-166, 2011.

[31] Y. Song, M. Zheng, L. Ma, and W. Shen. Anisotropic growth and formation mechanism investigation of 1D ZnO nanorods in spin-coating sol-gel process. J. Nanosci. Nanotechnol., 10(1):426-432, 2010.

${ }^{[32]}$ G.S. Wu, T. Xie, X.Y. Yuan, Y. Li, L. Yang, Y.H. Xiao, and L.D. Zhang. Controlled synthesis of ZnO nanowires or nanotubes via sol-gel template process. Solid State Commun., 134:485-489, 2005. 
${ }^{[33]}$ O. Marin, T. Soliz, J.A. Gutierrez, M. Tirado, C. Figueroa, and D. Comedi. Structural, optical and vibrational properties of $\mathrm{ZnO}: \mathrm{M}\left(\mathrm{M}=\mathrm{Al}^{3+}\right.$ and $\left.\mathrm{Sr}^{2+}\right)$ nano and micropowders grown by hydrothermal synthesis. J. Alloys Compd., 789:56$65,2019$.

${ }^{[34]}$ O. Marin, V. González, M. Tirado, and D. Comedi. Effects of methanol on morphology and photoluminescence in solvothermal grown $\mathrm{ZnO}$ powders and $\mathrm{ZnO}$ on Si. Mater. Lett., 251:41-44, 2019.

${ }^{[35]}$ Z. Liu, S. Liu, W. Wu, and C.R. Liu. Mechanism of controlled integration of ZnO nanowires using pulsed-laser-induced chemical deposition. Nanoscale, 11(6):2617-2623, 2019.

${ }^{[36]}$ K.M. McPeak, T.P. Le, N.G. Britton, Z.S. Nickolov, Y.A. Elabd, and J.B. Baxter. Chemical Bath Deposition of ZnO Nanowires at Near-Neutral pH Conditions without Hexamethylenetetramine (HMTA): Understanding the Role of HMTA in ZnO Nanowire Growth. Langmuir, 27(7):3672-3677, 2011.

[37] Y. Tak, and K. Yong. Controlled Growth of Well-Aligned ZnO Nanorod Array Using a Novel Solution Method. J. Phys. Chem. B., 109(41):19263-19269, 2005.

${ }^{[38]}$ J. Joo, B.Y. Chow, M. Prakash, E.S. Boyden, and J.M. Jacobson. Face-selective electrostatic control of hydrothermal zinc oxide nanowire synthesis. Nat. Mater., 10(8):596-601, 2011.

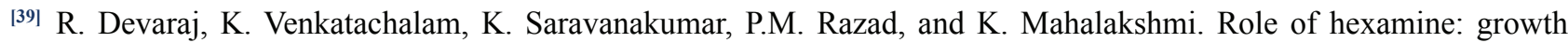
of multiarmed $\mathrm{ZnO}$ nanorods and evidence of merging due to lateral growth. J. Mater. Sci. - Mater. Electron., 27(11):12201-12208, 2016.

${ }^{[40]}$ A. Saranya, T. Devasena, H. Sivaram, and R. Jayavel. Role of hexamine in ZnO morphologies at different growth temperature with potential application in dye sensitized solar cell. Mater. Sci. Semicond. Process., 92:108, 2019.

${ }^{[41]}$ P. Nørby, M. Roelsgaard, M. Søndergaard, and B.B. Iversen. Hydrothermal Synthesis of CoSb $\mathrm{O}_{4}$ : In Situ Powder X-ray Diffraction, Crystal Structure, and Electrochemical Properties. Cryst. Growth Des., 16(2):834-841, 2016.

${ }^{[42]}$ E.D. Bøjesen, K.M.Ø. Jensen, C. Tyrsted, N. Lock, M. Christensen, and B.B. Iversen. In Situ Powder Diffraction Study of the Hydrothermal Synthesis of ZnO Nanoparticles. Cryst. Growth Des., 14(6):2803-2810, 2014.

${ }^{[43]}$ J.L. Lyons, A. Alkauskas, A. Janotti, and C.G. Van De Walle. Deep donor state of the copper acceptor as a source of green luminescence in ZnO. Appl. Phys. Lett., 111(4):042101/1-5, 2017.

${ }^{[44]}$ B. Ferrari, and R. Moreno. EPD kinetics: A review. J. Eur. Ceram. Soc., 30(5):1069-1078, 2010.

${ }^{[45]}$ L. Besra, and M. Liu. A review on fundamentals and applications of electrophoretic deposition (EPD). Prog. Mater. Sci., 52(1):1-61, 2007.

[46] P. Sarkar, and P.S. Nicholson. Electrophoretic Deposition (EPD): Mechanisms, Kinetics, and Application to Ceramics. J. Am. Ceram. Soc., 79(8):1987-2002, 1996.

[47] J.H. Dickerson, and A.R. Boccaccini. Electrophoretic Deposition of Nanomaterials. Springer, New York, 2012.

${ }^{[48]}$ P. Amrollahi, J.S. Krasinski, R. Vaidyanathan, L. Tayebi, and D. Vashaee. Chapter 17: Electrophoretic Deposition (EPD): Fundamentals and Applications from Nano- to Microscale Structures. In Handbook of Nanoelectrochemistry. Springer International Publishing Switzerland, 2015.

[49] M. Giersig, and P. Mulvaney. Formation of ordered two-dimensional gold colloid lattices by electrophoretic deposition. J. Phys. Chem., 97(24):6334-6336, 1993.

${ }^{[50]}$ M. Verde, M. Peiteado, A.C. Caballero, M. Villegas, and B. Ferrari. Electrophoretic Deposition of Transparent ZnO Thin Films from Highly Stabilized Colloidal Suspensions. J. Colloid Interface Sci., 373(1):27-33, 2012.

[51] M. Verde. EPD-deposited ZnO thin films: a review. Boletín de la Sociedad Española de Cerámica y Vidrio, 53(4):149$161,2014$.

${ }^{[52]}$ E.M. Wong and P.C. Searson. Kinetics of Electrophoretic Deposition of Zinc Oxide Quantum Particle Thin Films. Chem. Mater., 11(8):1959-1961, 1999. 


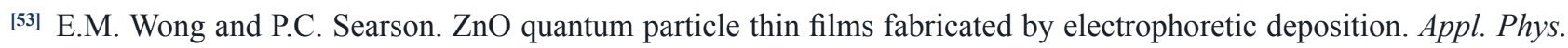
Lett., 74:2939-2942, 1999.

[54] Y.-C. Wang, I.-C. Leu, and M.-H. Hon. Preparation of Nanosized ZnO Arrays by Electrophoretic Deposition. Electrochem. Solid-State Lett., 5(4):C53-C55, 2002.

[55] Y.-C. Wang, I.-C. Leu, and M.-H. Hon. Effect of colloid characteristics on the fabrication of ZnO nanowire arrays by electrophoretic deposition. J. Mater. Chem., 12(8):2439-2444, 2002.

[56] Y.-C. Wang, I.-C. Leu, and M.-H. Hon. Size Control of ZnO Nanofibril within Template by Electrophoretic Deposition. Electrochem. Solid-State Lett., 7(10):D15-D18, 2004.

[57] Y.-C. Wang, I.-C. Leu, and M.-H. Hon. Kinetics of Electrophoretic Deposition for Nanocrystalline Zinc Oxide Coatings. J. Am. Ceram. Soc., 87(1):84-88, 2004.

${ }^{[58]}$ P. Lommens, D. Van Thourhout, P.F. Smet, D. Poelman, and Z. Hens. Electrophoretic deposition of ZnO nanoparticles, from micropatterns to substrate coverage. Nanotechnology, 19(24):245301, 2008.

[59] Y.-W. Chung, I.-C. Leu, J.-H. Lee, and M.-H. Hon. Filling behavior of ZnO nanoparticles into opal template via electrophoretic deposition and the fabrication of inverse opal. Electrochim. Acta, 54(13):3677-3682, 2009.

${ }^{[60]}$ L. Miao, S. Cai, and Z. Xiao. Preparation and characterization of nanostructured ZnO thin film by electrophoretic deposition from ZnO colloidal suspensions. J. Alloys Compd., 490(1-2):422-426, 2010.

[61] K. Wu, and I. Zhitomirsky. Electrophoretic Deposition of Ceramic Nanoparticles. Int. J. Appl. Ceram. Technol., 8(4):920-927, 2011.

${ }^{[62]}$ J.E. Qu, M. Ascencio, L.M. Jiang, S. Omanovic, and L.X. Yang. Improvement in corrosion resistance of WE43 magnesium alloy by the electrophoretic formation of a ZnO surface coating. J. Coat. Technol. Res., 1-12, 2019.

${ }^{[63]}$ S. Real, O. Espindola, O. Marin, D. Comedi, and M. Tirado. Novel nanostructures grown by electrophoretic deposition using Si substrates with low resistivity (58). In Electrophoretic Deposition VI: Fundamentals and Applications, A. Boccaccini, O. van der Biest, J. Dickerson (Eds), ECI Symposium Series (58), 2017.

${ }^{[64]}$ O. Espindola, S. Real, O. Marin, D. Comedi, and M. Tirado. Influence of substrate morphology on ZnO nanostructures grown by electrophoretic deposition (4). In Electrophoretic Deposition VI: Fundamentals and Applications, A. Boccaccini, O. van der Biest and J. Dickerson (Eds), ECI Symposium Series (4), 2017.

[65] Y.C. Wang, I.C. Leu, and M.H. Hon. Effect of colloid characteristics on the fabrication of ZnO nanowire arrays by electrophoretic deposition. J. Mater. Chem., 12(8):2439-2444, 2002.

[66] Y.C. Wang, I.C. Leu, and M.H. Hon. Dielectric property and structure of anodic alumina template and their effects on the electrophoretic deposition characteristics of ZnO nanowire arrays. J. Appl. Phys., 95(3):1444-1449, 2004.

${ }^{[67]}$ D.W. Bahnemann, C. Kormann, and M.R. Hoffmann. Preparation and characterization of quantum size zinc oxide: a detailed spectroscopic study. J. Phys. Chem., 91(14):3789-3798, 1987.

${ }^{[68]}$ J. Tabellion, and R. Clasen. Electrophoretic deposition from aqueous suspension for near-shape manufacturing of advanced ceramics and glasses-applications. J. Mater. Sci, 39:803-811, 2004.

${ }^{[69]}$ L. Besra, and M. Liu. Electrophoretic Deposition on Non-Conducting Substrates: The Case of YSZ Film on NiO-YSZ Composite Substrates for Solid Oxide Fuel Cell Application. J. of Power Sources, 173(1):130-136, 2007.

${ }^{[70]}$ Y. Yang, X.W. Sun, B.K. Tay, P.H.T. Cao, J.X. Wang, and X.H. Zhang. Revealing the surface origin of green band emission from $\mathrm{ZnO}$ nanostructures by plasma immersion ion implantation induced quenching. J. Appl. Phys., 103(6):064307, 2008.

[71] W.K. Hong, B.J. Kim, T.W. Kim, G. Jo, S. Song, S.S. Kwon, A. Yoon, E.A. Stach, and T. Lee. Electrical properties of $\mathrm{ZnO}$ nanowire field effect transistors by surface passivation. Colloids Surf. A: Physicochem. Eng. Aspects, 313314(1):378-382, 2008.

${ }^{[72]}$ L. Qin, C. Shing, S. Sawyer, and P.S. Dutta. Enhanced ultraviolet sensitivity of zinc oxide nanoparticle photoconductors by surface passivation. Opt. Mater., 33(3):359-362, 2011. 
${ }^{[73]}$ L. Guo, S. Yang, C. Yang, P. Yu, J. Wang, W. Ge, and G.K.L. Wong. Highly monodisperse polymer-capped ZnO nanoparticles: Preparation and optical properties. Appl. Phys. Lett., 76(20):2901-2903, 2000.

${ }^{[74]}$ H.Y. Yang, S.F. Yu, G.P. Li, and T. Wu. Random lasing action of randomly assembled ZnO Nanowires with MgO coating. Opt. Express, 18(13):13647-13654, 2010.

[75] Y. Wu, W. Wu, X.M. Zou, L. Xu, and J.C. Li. Growth and great UV emission improvement of highly crystalline quality core-shell $\mathrm{ZnO} / \mathrm{MgO}$ nanowires. Mater. Lett., 84:147-150, 2012.

${ }^{[76]}$ N.C. Vega, O. Marin, E. Tosi, G. Grinblat, E. Mosquera, M.S. Moreno, M. Tirado, and D. Comedi. The shell effect on the room temperature photoluminescence from $\mathrm{ZnO} / \mathrm{MgO}$ core/shell nanowires: exciton-phonon coupling and strain. Nanotechnology, 28(27):275702, 2017.

${ }^{177]}$ G. Grinblat, F. Bern, J. Barzola-Quiquia, M. Tirado, D. Comedi, and P. Esquinazi, Luminescence and electrical properties of single $\mathrm{ZnO} / \mathrm{MgO}$ core-shell nanowires. Appl. Phys. Lett., 104:103113, 2014.

${ }^{[78]}$ C.Y. Liu, H.Y. Xu, J.G. Ma, X.H. Li, X.T. Zhang, Y.C. Liu, and R. Mu. Electrically pumped near-ultraviolet lasing from $\mathrm{ZnO} / \mathrm{MgO}$ core/shell nanowires. Appl. Phys. Lett., 99(6):063115, 2011.

${ }^{[79]}$ Z.F. Shi, Y.T Zhang, X.J. Cui, S.W. Zhuang, B. Wu, X.W. Chu, X. Dong, B.L. Zhang, and G.T. Duab. Photoluminescence performance enhancement of $\mathrm{ZnO} / \mathrm{MgO}$ heterostructured nanowires and their applications in ultraviolet laser diodes. Phys. Chem. Chem. Phys., 17(21):13813-13820, 2015.

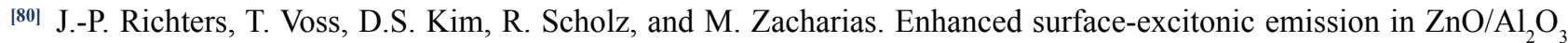
core-shell nanowires. Nanotechnology, 19(30):305202, 2008.

${ }^{[81]}$ D. Bozyigit, N. Yazdani, M. Yarema, O. Yarema, W.M.M. Lin, S. Volk, K. Vuttivorakulchai, M. Luisier, F. Juranyi, and V. Wood. Soft surfaces of nanomaterials enable strong phonon interactions. Nature, 531(7596):618-622, 2016.

\section{Bios}

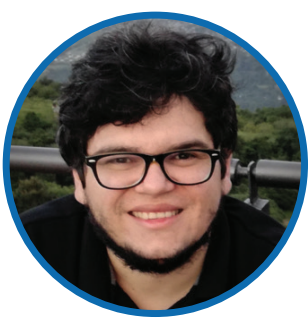

\section{Oscar Marin}

Oscar Marin graduated as Chemist at the University of Quindío (Colombia) in 2007 and as Doctor in Chemistry at the National University of the Littoral (Argentina) in 2013 with scholarships from ANPCyT and CONICET. He obtained a postdoctoral scholarship from CONICET in 2013 and joined the Nanoproject group at the National University of Tucumán (Argentina). He moved to the University of Chile in 2015 to lead a postdoctoral project funded by Fondecyt, and returned to Argentina in 2017 to become a researcher of CONICET. His research interests include the synthesis, characterization and applications of nanostructured materials, mainly semiconductors.

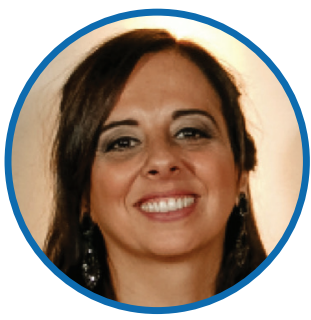

\section{Silvina C. Real}

Silvina Real is Associate Professor at the National University of Tucumán (UNT), Argentina and a researcher in the Nanoproject Group, INFINOA,
CONICET-UNT. She received her PhD in Exact Sciences and Engineering in 2017 at UNT, with a thesis in Physics directed by Mónica Tirado and David Comedi. Her research topic are nanostructures manufacture by electrophoretic deposition and the application of mathematical models

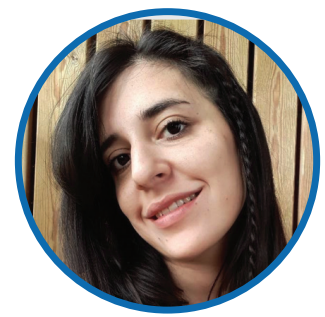

Nadia Celeste Vega

Nadia Celeste Vega graduated as Physicist (2012) at the National University of Tucumán (UNT), Argentina, where she also obtained her $\mathrm{PhD}$. She is currently a teaching assistant at the Physics Department of that house of studies. Her PhD thesis, about $\mathrm{ZnO}$ nanostructures and their applications in optoelectronic devices, was honored with the First Mention by the Jorge Sábato Institute award. Between 2017 and 2019, she was a postdoctoral fellow at INQUINOA (CONICET-UNT). She participated in collaborations and research stays at the University of Oxford (England), UNICAMP (CampinasBrazil) and ICMAB (Barcelona-Spain). Currently, she is an Assistant Researcher at INFINOA (CONICET-UNT), where she is working on the integration of semiconductor nanostructures in solar cells. 


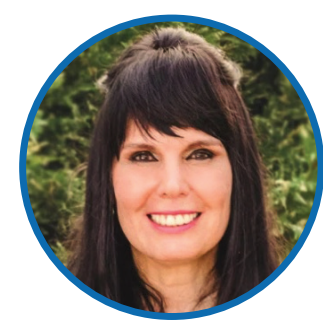

Mónica Tirado

Full Professor at the National University of Tucumán (UNT), Argentina; Independent Researcher of CONICET, director of the Laboratory of Nanomaterial and co-director of the research group NANOPROJECT (INFINOA:CONICET-UNT). She received the award J.J.GIAMBIAGI 2004 for Best Doctoral Thesis in Argentina. She has published over 40 works in international journals and 25 papers in proceedings. She has presented more than 200 research works in national and international congresses. She has supervised $7 \mathrm{Ph}$. D. students. She spoke at a TEDx talk called "Llegando al Corazón de la Materia" (2015). Her main research topic is the manufacture and characterization of semiconductor nanostructures to obtain nanodevice prototypes.

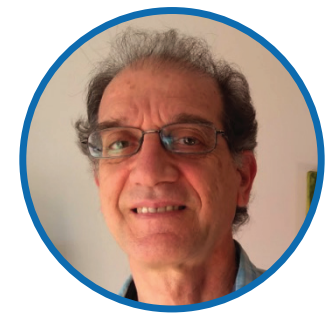

David Comedi

David Comedi obtained his $\mathrm{PhD}$ in Physics in 1990 at the Israel Institute of Technology, Technion, and completed his postdoctoral work at the Centre for Electrophotonic Materials and Devices, McMaster University, Canada. After many years as Professor of Physics at UNICAMP, Brazil, he was repatriated in 2006 by CONICET as an Independent Investigator working at the National University of Tucumán (UNT). Currently, he is a Principal Investigator of CONICET, Associate Professor at the Physics Department of UNT, Director of the NanoProject group and Head of the Physics Institute of Northwestern Argentina (INFINOA-CONICET/UNT). His scientific contributions are focused on the fields of ion-solid interactions and semiconductor nanotechnology 